\title{
OPTIMAL DEBT AND EQUILIBRIUM EXCHANGE RATES IN A STOCHASTIC ENVIRONMENT: AN OVERVIEW
}

\author{
JEROME L. STEIN
}

CESIFO WORKING PAPER NO. 1363

CAtegory 5: Fiscal Policy, MaCroeconomics AND Growth DECEMBER 2004

\footnotetext{
An electronic version of the paper may be downloaded

- from the SSRN website: Www.SSRN.com

- from the CESifo website: www.CESifo.de
} 


\title{
OPTIMAL DEBT AND EQUILIBRIUM EXCHANGE RATES IN A STOCHASTIC ENVIRONMENT: AN OVERVIEW
}

\begin{abstract}
The focus is upon equilibrium real exchange rates, optimal external debt and their interaction, in a world where both the return on investment and the real rate of interest are stochastic variables. These theoretically based measures are applied empirically to answer the following questions: What is a theoretically based empirical measure of an "excess debt" that increases the probability of a debt crisis? What is a theoretically based empirical measure of a "misaligned" exchange rate that increases the probability of a currency/balance of payments crises? Two theoretical tools are used to derive Early Warning Signals. One is the NATREX model to estimate the equilibrium real exchange rate. The second is stochastic optimal control/dynamic programming to derive the optimal debt and endogenous growth rate. Examples are given of these applications.
\end{abstract}

JEL Code: C61, D9, D81, F3, F4, F31, F34.

Keywords: stochastic optimal control, foreign debt, NATREX, vulnerability to external shocks, sustainable current account, warning signals of debt crisis, exchange rate misalignments.

\author{
Jerome L. Stein \\ Division of Applied Mathematics \\ Box $F$ \\ Brown University \\ Providence RI 02912 \\ USA \\ jerome_stein@brown.edu
}

This draft benefited greatly from the advice of: Peter Clark, TEAM/CNRS Université Paris 1, Panthéon-Sorbonne, Karlhans Sauernheimer, Christoph Fischer, Balazs Égert, Giancarlo Gandolfo. 
Optimal debt and equilibrium exchange rates in a Stochastic Environment: An Overview Jerome L. Stein

The focus of this book ${ }^{1}$ is upon real exchange rates, external debt and their interaction in an environment where both the return on capital and the real rate of interest are stochastic variables. The dynamic interaction between exchange rates and debt occurs because an "overvalued" exchange rate leads to a steady rise in the external debt. In turn, the accumulation of the debt and the transfer payments on the debt exert downward pressure on the exchange rate, which may lead to a currency (balance of payments) crisis. Moreover, a significant depreciation of the currency increases the debt burden and increases the probability of a debt crisis.

This overview chapter explains in general terms the relevance and the contributions of this book to economic theory and policy. The economic theory and mathematics developed in chapters two and three derive benchmarks for the optimal debt, and for the equilibrium exchange rate in chapter four. These benchmarks are applied in chapters five through nine to answer the following questions.

- What is a theoretically based empirical measure of an "excess" debt that increases the probability of a debt crisis?

- What is a theoretically based empirical measure of a "misaligned" exchange rate that increases the probability of a currency crisis?

Several historical examples indicate the significance of these questions. Then we sketch how the powerful analytical tools are used to answer these questions in a stochastic environment, where the return on capital and real interest rate are not predictable.

In July 1997, the economies of East Asia became embroiled in one of the worst financial crises of the postwar period. Yet, prior to the crisis, these economies were seen as models of economic growth experiencing sustained growth rates that exceeded those earlier thought unattainable. Similarly in 1998, the financial markets, the economics profession and the International Monetary Fund viewed Argentina as a model of stability and growth. In 2001- 02 the Argentine economy defaulted on its huge debt.

\footnotetext{
${ }^{1}$ Jerome L. Stein, Stochastic Optimal Control, International Finance and Debt Crises, Oxford University Press, forthcoming.
} 
Why did the financial markets, the International Monetary Fund, the World Bank and the bond rating agencies fail to anticipate the crises? In 2004, the International Monetary Fund Independent Evaluation Office IEO published a report that reviewed why and how, despite the Fund's extensive involvement with Argentina, the Fund was not able to help Argentina prevent and better manage the crisis. The primary purpose of the IEO evaluation is to draw lessons for the Fund in its future operational work.

The IEO report stated (pp. 22-23) that there is a general agreement that a combination of several external and internal factors contributed to the crisis: (i) weak fiscal policy, (ii) rigid exchange rate regime, and (iii) vulnerability to adverse external shocks. The IEO could not isolate the relative importance of these factors. "In the absence of the underlying vulnerability...the same adverse developments would not have had the catastrophic effects that were associated with the crisis, though they may well have produced some negative effects."

The factors underlying vulnerability must be given precise theoretical meaning with associated operational measures, to evaluate their explanatory power. The objective is to arrive at theoretically justified Early Warning Signals, based upon available information. The main reasons for the failures to anticipate balance of payments and debt crises were that the theories were based upon deterministic models, which ignored uncertainty, or that the theoretical tools were unduly limited in scope. For example, the most frequently used method to evaluate whether an exchange rate was misaligned was to compare the exchange rate with its Purchasing Power Parity (PPP) value. The PPP hypothesis assumes that the "equilibrium" real exchange rate is constant, but it does not provide a theory to explain what is the equilibrium real exchange rate. Moreover, this hypothesis lacks explanatory power ${ }^{2}$. Empirical measures to estimate overvaluation compared the real exchange rate to its trend value ${ }^{3}$. These eclectic empirical measures just add a trend to the PPP but cannot convey information if an appreciation of the real exchange rate is a sign of strength or weakness in the balance of payments.

The most widely used measures of excess debt, which may lead to a debt crisis, focus upon two variables: (i) The ratio of debt/GDP that would result if current policies

\footnotetext{
${ }^{2}$ See Duval (2002).

${ }^{3}$ See Kaminsky and Reinhart (1999).
} 
continued into the future. (ii) The trade balance/GDP that would keep the debt/GDP ratio equal to its current ratio. It is hypothesized that the higher the number, the more likely is it that there would be a debt problem. Empirical researchers concluded that these measures lacked explanatory power.

Since both measures of overvalued exchange rates and excess debt or debt burden were inadequate, the implied early warning signals were unreliable. A question that is relevant for policy is: what are theoretically based, operational Early Warning Signals that have explanatory power? One motive in writing this book is to answer this question.

Two theoretical tools are developed in this book. The analytical tool to estimate and explain the "equilibrium" real exchange rate is the NATREX model, an acronym for the natural real exchange rate. This is positive economics. The analytical tool to derive the optimal external debt/net worth and expected growth rate in an environment where both the productivity of capital and the real interest rate are stochastic is stochastic optimal control dynamic programming (SOC/DP). This is normative economics. Both are benchmarks of performance. We then explain the interaction between misaligned exchange rates and excess debt that increase the probability of crises. In part 7, we sketch the eclectic-econometric literature concerning currency and debt crises and compare that approach with our theoretically based approach.

The Central and Eastern European Countries CEEC are planning to join the European Monetary Union. These countries must establish the nominal values of their currencies upon entering Exchange Rate Mechanism, ERM-II. How should one evaluate the appropriateness of their nominal and real exchange rates? In the last ten years, the real values of their currencies measured in terms of tradable goods have been appreciating relative to the Euro. A correctly chosen exchange rate is a prerequisite for avoiding the depressing effects that occurred with the German reunification. An overvalued exchange rate hinders real growth, leads to sustained current account deficits and a large external debt. These factors could lead to either a debt crisis or a currency crisis. If the CEEC run into financial difficulties then, unlike the Eastern part of Germany which has been supported by the Western part, their debts will not be forgiven by the other members. There is an explicit "no bail- out" clause in the Maastricht treaty (article 104b) that the CEEC signed when entering the EU. Moreover, if the exchange rate "disequilibrium" is 
sufficiently great, these countries may be forced to exit from the peg. An undervalued exchange rate would generate inflationary pressures that would violate the Maastricht criteria for entry into ERM II. We use the NATREX model developed in chapter four to evaluate what is an equilibrium exchange rate and to explain the appreciation of the real exchange rates of the CEEC: do they reflect strengths or are they Warning Signals of currency or debt crises? This question cannot be answered if "misalignment" is measured as the deviation of the real exchange rate from its trend.

Equilibrium exchange rates and sustainable debts are not only relevant to the CEEC and to the emerging markets, but also to the entire Euro area and to the United States. The real value of the Euro relative to the US dollar has fluctuated drastically since its inception. A frequently discussed question is whether the value of the euro has been "misaligned", and what is desirable policy? A benchmark, the "equilibrium" real exchange rate, is required to answer this question.

The United States current account has been deeply in deficit in recent years. The growing negative net investment position leads to the question: how sustainable is the US current account deficit and associated inflow of capital? Alternatively, one should ask: is the US debt ratio excessive relative to the derived optimal debt ratio?

The optimality analysis is based upon state of the art techniques of stochastic optimal control/dynamic programming (SOC/DP). The reasons for using these techniques are that: (1) Optimization involves inter-temporal decisions. Current decisions not only affect current welfare, but they also have consequences for future welfare. (2) The future is unpredictable, so that the optimal controls or decisions made at any instant enter as feedback functions of the currently observable state.

The dynamic programming/stochastic optimal control techniques are widely used in the mathematical finance literature published in applied mathematics journals ${ }^{4}$, but are not widely used by economists. The stochastic optimal control techniques that we use to derive the optimal debt are quite technical. An attractive feature of our analysis of the optimal long term debt and expected endogenous growth is that we are able to show how the SOC/DP equations can be understood in terms of a mean variance M-V approach to

\footnotetext{
${ }^{4}$ See American Mathematical Society, Contemporary Mathematics, Mathematics of Finance (2004). Merton's book on continuous time finance uses these techniques extensively.
} 
portfolio selection. Thereby a relatively intuitive and graphic explanation - based upon the $\mathrm{M}-\mathrm{V}$ techniques known to economists - can be given for the mathematical results.

An operational measure of the optimal debt/net worth ratio is derived using SOC/DP. As the actual debt ratio rises above the optimal, the expected growth rate of consumption declines and its variance rises. The actual debt is generated by current account deficits, equal to an excess of investment less social saving. Fiscal and monetary policies are important determinants of investment less social saving. We believe that if the attempt to service the external debt leads to a significant and sustained decline in consumption, the country will default - there will be a debt crisis. It follows that as the debt ratio rises above the optimal, the probability of a debt crisis increases. The meaning of vulnerability is that random events, subsumed under the variance of the growth rate, would make the actual growth rate of consumption negative if the debt is serviced.

Considerable attention is devoted to spelling out the interactions between misaligned exchange rates and excessive debt, as these are crucial to the understanding of the macroeconomic determinants of crises. There are several reasons why we need an operational concept of an "equilibrium" exchange rate ${ }^{5}$. First: we would like to know where exchange rates are heading. Second: in the context of fixed exchange rate arrangements, such as countries (CEEC) entering into a monetary union or countries that have selected hard pegs, it is important to know whether a particular exchange rate is sustainable. Will the rate selected be consistent with a "satisfactory" rate of capacity utilization and with relative price stability. Third: what factors have produced observed changes in real exchange rates? Are they the result of exogenous forces such as the terms of trade or are they the results of policies followed. If the latter, how do the controllable policies affect the exchange rates?

Our theme and contributions can be summarized.

(1) The focus is upon equilibrium real exchange rates, optimal external debt and their interaction. (2) Explicit models/transmission mechanisms are specified that explain how the dependent variables - the real exchange rate and the external debt - are affected by the exogenous and control/policy variables. A "story"/scenario is an integral part of the analysis.

\footnotetext{
${ }^{5}$ See the paper by Driver and Westaway on concepts of equilibrium exchange rates.
} 
(3) Key issues are whether the real exchange rate is "misaligned" or whether the debt deviates from its optimal value.

(4) Explicit empirical measures of "misalignment" and "excessive debt" are derived from the theory.

(5) On the basis of the NATREX theory, the equilibrium real exchange rate can be written as $\mathrm{R}[\mathrm{Z}(\mathrm{t})]$, where a rise is an appreciation and $\mathrm{Z}(\mathrm{t})$ is a vector of measurable exogenous and control/policy real fundamentals that may vary over time. Misalignment $\Phi(\mathrm{t})=\mathrm{R}(\mathrm{t})-\mathrm{R}[\mathrm{Z}(\mathrm{t})]$ is the difference between the actual real exchange rate $\mathrm{R}(\mathrm{t})$ and the NATREX.

(6) The actual exchange rate differs from the NATREX because of speculative, cyclical, and other ephemeral influences with zero expectations. Therefore, the real exchange rate will converge to a band which contains the NATREX. Specifically, the trends in the NATREX explain the trends in the real exchange rate. This tells us which way the exchange rate is going. If measured misalignment overvaluation, $\Phi(t)>0$ is "sufficiently" large and sustained and the nominal exchange rate is pegged, a currency crisis is likely to occur. Similarly, if there is a significant undervaluation $\Phi(\mathrm{t})<0$ and a pegged nominal exchange rate, then there will be significant inflationary pressure.

(7) The theoretical literature uses the Maximum Principle of Pontryagin or the Intertemporal Budget Constraint (IBC) to derive optimality conditions ${ }^{6}$. The Maximum Principle is based upon perfect certainty. The trajectory to the steady state is unique, so that there is saddle point instability if there are any errors, however slight. The IBC literature is based upon certainty equivalence. These measures are inappropriate because we live in a world of uncertainty, the future is unpredictable and agents are risk averse. It is inappropriate to use "certainty equivalence". The IBC is unknowable, not operational and not enforceable. Instead, the techniques of stochastic optimal control/dynamic programming SOC/DP are used in this book to derive "inter-temporal optimization". We derive the optimal external debt/net worth, capital/net worth, consumption/net worth and the optimal endogenous expected growth rate in a stochastic environment.

(8) The optimal debt/net worth $\mathrm{f}^{*}$ or capital/net worth, derived from the SOC/DP analysis

\footnotetext{
${ }^{6}$ Gandolfo and Turnovsky review the literature. Infante and Stein showed that this literature requires perfect knowledge and certainty, and showed that dynamic programming is a very much better method to derive inter-temporal optimality conditions.
} 
is measurable for any arbitrary risk aversion. An excessive debt $\Psi_{\mathrm{t}}=\mathrm{f}_{\mathrm{t}}-\mathrm{f}^{*}{ }_{\mathrm{t}}$ is the deviation of the actual debt ratio $\mathrm{f}_{\mathrm{t}}$ from $\mathrm{f}^{*}$ the optimal ratio.

(9) The greater is the measured excessive debt $\Psi_{t}$ the lower is the expected growth rate of consumption and the higher is its variance. It is therefore the more likely is it that random external shocks will lead to a debt default.

(10) The two types of crises are interrelated. A currency depreciation increases the real external debt burden, which raises the probability of a debt crisis. A debt burden adversely affects the current account and capital flows, which exert pressure on the exchange rate. We give precision to the concept of "vulnerability" to adverse developments on the basis of two measures.

Excess debt $\quad \Psi_{\mathrm{t}}=\mathrm{f}_{\mathrm{t}}-\mathrm{f}^{*}{ }_{\mathrm{t}}>0 \Rightarrow$ probability of debt crisis increases

Misalignment $\quad \Phi_{\mathrm{t}}=\mathrm{R}_{\mathrm{t}}-\mathrm{R}\left[\mathrm{Z}_{\mathrm{t}}\right]>0 \Rightarrow$ probability of currency crisis increases;

Interaction Probability of currency crisis $\Leftrightarrow$ Probability of debt crisis

A "guided tour" of our contributions starts with the analyses of both optimal short-term (part 2) and long-term external debt (part 3). A measure of excess debt $\Psi_{\mathrm{t}}$ is derived in each case. Empirical examples of excess debt and Early Warning Signals of a debt crisis derived from the theoretical analyses are given (part 4) for emerging markets and Latin America. The next part of the "guided tour" concerns the equilibrium exchange rates, based upon the NATREX model (part 5). A measure of misalignment is derived based upon this model. The relation between the Purchasing Power Parity (PPP) hypothesis and the NATREX is explained. An example is provided showing how the NATREX model explains the medium to longer run movements in the real exchange rate of the Dollar-Synthetic Euro (part 6). Finally, the interaction between misaligned exchange rates $\Phi$ and excessive debt $\Psi$ is shown (part 7) for the 1997-98 crisis in Thailand. This example illustrates the contribution of our analysis, relative to that found in the eclectic-econometric literature, in providing Early Warning Signals of balance of currency and debt crises.

\section{Optimal Debt Models}

A major source of the private capital flow is direct investment, which is longterm investment. It is the least volatile, whereas the most volatile component of the 
private flow is bank loans, which is short-term investment. Countries have both types of debt, and the optimal amounts differ according to the type. The inter-temporal optimization problem arises because the debt occurred to finance consumption and investment at one time affects the consumption possibilities at a later date. This choice is seen in equations (1) and (2).

In the case of short-term investment if the borrowing is at time $t$ then it must be repaid with interest at later date $s=t+\Delta t$. In the case of long-term investment, the debt does not have to be repaid at any terminal date, but must be serviced regularly. Equation (1) describes the change in the debt $d L_{t}$. External debt $L_{t}$. rises because consumption $C_{t}$ plus investment $I_{t}$ plus the debt service $r_{t} L_{t}$ exceeds $Y_{t}$ the GDP. Alternatively, the change in the debt is $\left(I_{t}-S_{t}\right) d t$, investment $I_{t}$ less saving $S_{t}=Y_{t}-r_{t} L_{t}-C_{t}$ over the period of length $d t$.

(1) $d L_{t}=\left(I_{t}-S_{t}\right) d t=\left(C_{t}+I_{t}+r_{t} L_{t}-Y_{t}\right) d t=$ current account deficit

Fiscal and monetary policies are important determinants of investment and social saving by the private plus public sectors. In the Latin American countries the debt has risen due to high consumption and/or low social saving by the public plus the private sectors. In the Asian countries industrial policy stimulated private investment The excess of investment less saving leads to a capital inflow and an increase in the external foreign currency denominated debt.

The external debt has to be serviced and that would clearly affect future consumption. We can see this by writing consumption at some later time $s=t+d t$, in equation (2) below ${ }^{7}$. Consumption is equal to the GNP, which is equal to the GDP less the debt service $Y_{s}-r_{s} L_{s}$, less investment $I_{s}$ plus new borrowing $d L_{s}$. The new borrowing is the net capital inflow in the form of either direct investment, portfolio investment or short term bank flows.

(2) $C_{s} d s=\left(\boldsymbol{Y}_{\boldsymbol{s}}-\boldsymbol{r}_{s} L_{s}-I_{s}\right) d s+d L_{s}$

Three elements must be specified to solve the inter-temporal optimization problem. Different models involve different specifications of these three elements.

\footnotetext{
${ }^{7}$ It is another way of writing equation (1), but at a later date.
} 
(i) The constraints and controls/policy decisions.

(ii) The dynamic stochastic process

(ii) The optimality criterion

In chapter two, the debt is modeled as short-term corresponding to bank loans. In the model discussed in chapter three, the debt is long term, which would correspond to direct investment or long-term portfolio investment. The major theoretical difference concerns the constraints, so that the mathematical analysis is very different in each case. They must be modeled differently, and one case cannot be modeled as a special case of the other, for the following reason.

In the short-term debt model sketched in part 2 below, debt is incurred in period $\mathrm{t}$ $=1$ which has a maturity at period $t=2$. It is a repeating two period model. There are several constraints. The first is that at maturity, the debt must be repaid with interest. The second is that the capital at the beginning of period $t=3$ must be the same as it was at the beginning of $\mathrm{t}=1$, so the process is repeated. The third is that consumption in period $\mathrm{t}=2$, when the debt is repaid, must exceed a certain minimum - regardless of the state of nature. This is a "no bankruptcy" constraint. The argument is that, if the attempt to service the debt would reduce consumption below the minimum - which we arbitrarily set at zero - then the country would default. Faced with a choice: (a) repay debt and drastically reduce the standard of living, or (b) default but do not drastically reduce the standard of living, the economy would select the second option. The controls/policies are the consumption, investment and resulting debt in period $t=1$, subject to the constraints.

In the long-term model of chapter three, sketched in part 3 below, there is no maturity to the debt but it must always be serviced. It is an infinite horizon model in continuous time. The controls - debt, capital and consumption - are constantly adjusted to keep these control/policy variables at their derived optimum levels. The constraint is that consumption always be positive, regardless of the state of nature. This inter-temporal optimization involves the use of dynamic programming.

In both cases, a debt crisis is produced when the actual debt significantly exceeds the constrained optimal debt. The actual debt is generated by saving and investment decisions by the private and public sectors, which may be far from optimal. The economy 
is more vulnerable to external shocks when the actual debt significantly exceeds the constrained optimal debt.

The second specification concerns the stochastic process. Two stochastic variables - real GDP and real interest rate - will affect consumption at the later date. They are written in bold letters in equation (2). Each one is highly variable. If bad shocks reduce the GDP and raise real interest rates, and investment falls to a minimum level then consumption in equation (2) may have to be reduced - unless there is new borrowing to offset the decline. We model the two sources of uncertainty that ultimately affect consumption. The first source of uncertainty is the ratio of GDP per unit of capital $Y_{t} / K_{t}$ and the second source is the real rate of interest $r_{t}$.

The output/capital ratio $Y_{t} / K_{t}=b_{t}$ has a deterministic component $b$, which is the mean return on capital, and a stochastic component with a zero mean and a significantly positive variance. The deterministic component $b$ corresponds to the slope of a regression of the growth of GDP on the ratio of investment/GDP, and the stochastic part corresponds to the standard error of estimate. This stochastic part contains the "Solow residual", variations in the rate of capacity utilization resulting from fiscal and monetary policies, variations in the terms of trade and the composition and quality of the investments.

The second source of uncertainty concerns the real interest rate $r_{t}$ required to service the external debt $L_{t}$. For countries other than the US - such as emerging market countries - the real interest rate in terms of consumer goods $r_{t}$ has three components. The first is the interest rate on US Treasury long-term debt. The second is the premium on dollar denominated debt charged to sovereign borrowers. The third is the anticipated exchange rate depreciation of the currency. A currency depreciation increases the amount of consumer goods that must be sacrificed to service/repay the foreign currency denominated debt. The equation for the real interest rate contains two terms: the first term is deterministic with a mean real rate of interest $r$ and the second term is stochastic with a positive variance.

The expectations of the stochastic terms are equal to zero, but the productivity of capital and real rate of interest may be correlated. In developed countries such as the United States and Europe, the correlation is generally positive. In periods of rapid 
growth, there is a rise in investment demand and demand for money; and interest rates rise. When there are financial crises, whether in the United States during the Great Depression or during financial crises in Asia or Latin America, the growth of GDP and real interest rate are negatively correlated, for the following reason. A decline in GDP may occur because of a decline in the terms of trade and/or the anticipated return on investment turns out to be an illusion and the asset bubble collapses. The stochastic term in the productivity of capital equation is negative. Since firms borrow primarily from the banks to finance real investment and the banks in turn primarily finance their loans by borrowing US dollars in the international capital market, a domino effect is created in the event of a financial panic. When debtors are unable to repay their loans to the banks, the banks in turn are unable to repay their loans to international creditors. Financial panic leads to a short term capital flight. The government may try to stem the outflow by using the dollar reserves, but that is only a stopgap measure. Sooner or later the monetary authorities will raise interest rates and, when that fails to stem the outflow, the currency will depreciate. The depreciation of the currency implies that the real rate of interest to repay a debt denominated in foreign currency rises. In that event, the stochastic term in the real interest rate equation is positive. The situation is exacerbated when banks also denominate their loans to the domestic firms in US dollars. Firms would find it very difficult to service debts denominated in foreign currency because they are faced with both a rising nominal rate of interest and a depreciating currency. A negative correlation between the productivity of capital $b_{t}$ and the real rate of interest $r_{t}$ makes an external debt very risky.

Faced with these sources of uncertainty, how then should a country select its optimal debt and level of consumption? The third specification concerns the optimality criterion. One criterion is that the controls are selected to maximize the expectation of the discounted value of a concave utility of consumption over the appropriate horizon. A second criterion is that the debt and capital are selected to maximize the expected value of the growth rate of consumption over a horizon, subject to the constraint that the ratio of consumption/net worth is a positive constant. A third criterion is a very conservative one. The controls are selected to maximize the minimum expected value of the utility of 
consumption ${ }^{8}$. Only the first two criteria are used in this book.

\section{Short-debt model in Discrete Time Finite Horizon}

For many countries, short-term capital flows are important in financing investment less saving and have been associated with crises, such as in Southeast Asia 1997-98. In this part, we sketch the derivation of the optimal investment, consumption and debt in the short-term capital movements model (STCM), which is the subject of chapter two. Explicit equations for excess debt $\Psi_{\mathrm{t}}$ and Early Warning Signals of a debt crisis are stated. In part 4, we provide specific examples of how this analysis can explain the default risk in emerging market countries and Latin America. Detailed empirical application of the STCM is the subject of chapter five.

The model assumes two repeating discrete time periods. In period one, the country has a stock of capital $\mathrm{K}_{1}$ and a Gross Domestic Product $\mathrm{Y}_{1}$. The controls are consumption $\mathrm{C}_{1}$ and investment $\mathrm{I}_{1}$. If consumption plus investment is greater than the GDP, the country incurs an external debt $\mathrm{L}_{1}$ to finance the difference. If consumption plus investment is less than the GDP the country is an international creditor, and the debt $\mathrm{L}_{1}$ is negative. The debt, or net foreign assets, bears a known real rate of interest ${ }^{9}$. At the second period, the debt plus interest must be repaid. We consider a repeating two period model, so that the capital at the beginning of period three must be the same as it was at the beginning of period one. This constraint means that the sum of investment over the two periods must be zero.

The productivity of capital $Y_{t} / K_{t}=b_{t}$ is a stochastic variable. When the investment decision $I_{1}$ is made in period one, the productivity of capital in period two $b_{2}=Y_{2} / K_{2}$ is unknown. Capital in period two is the capital at the beginning of period one plus the investment made in period one. Two possibilities are considered. Either the productivity of capital in period two $b^{+}$exceeds the interest rate $\mathrm{r}$, with probability $1>\mathrm{p}>0$, or the productivity of capital $b^{-}$is less than the rate of interest with probability (1-p).

The debt in period one $\mathrm{L}_{1}$ finances investment $I$ less saving $S$. The stochastic variable $b_{2}$ is written in bold letters. Consumption in period two $\mathrm{C}_{2}$ is equal to the GDP in

\footnotetext{
${ }^{8}$ See Fleming (2005).

${ }^{9}$ This assumption is relaxed in the long term optimal debt model in part 3 .
} 
period two $\mathrm{Y}_{2}=\mathbf{b}_{2} \mathrm{~K}_{2}=\mathbf{b}_{2}\left(\mathrm{~K}_{1}+\mathrm{I}_{1}\right)$ less the repayment of the debt plus interest $(1+\mathrm{r}) \mathrm{L}_{1}$ plus the disinvestment to make capital at the beginning of period three equal to the initial capital $K_{1}$. Equation (3) describes consumption $\mathrm{C}_{2}$ in period two. Since the return on capital can assume two values: $\mathbf{b}^{+}>\mathrm{r}$ in the good case, and $\mathbf{b}^{-}<\mathrm{r}$ in the bad case, consumption in period two can assume either $\mathrm{C}_{2}{ }^{+}$in the good case or $\mathrm{C}_{2}{ }^{-}$in the bad case. (3) $\mathbf{C}_{2}=\mathbf{b}_{2} \mathrm{~K}_{1}+\left[(1+\mathrm{r})\left(\mathrm{b}_{1} \mathrm{~K}_{1}-\mathrm{C}_{1}\right)\right]+\left(\mathbf{b}_{2}-\mathrm{r}\right) \mathrm{I}_{1}$.

There are three components to consumption in period two, equation (3). If there is neither saving $\left(\mathrm{S}_{1}=\mathrm{b}_{1} \mathrm{~K}_{1}-\mathrm{C}_{1}\right)$ nor investment in period one - if consumption is equal to GDP in the first period - then consumption in period two would just be the GDP in period two $\mathrm{Y}_{2}=\mathbf{b}_{2} \mathrm{~K}_{1}$.

If there is saving but no investment in period one, then consumption in period two is the sum of the first two terms. The saving is invested abroad at the known rate of interest, and permits the economy to consume $\left[(1+\mathrm{r})\left(\mathrm{b}_{1} \mathrm{~K}_{1}-\mathrm{C}_{1}\right)\right]$. This term is not stochastic.

If there is investment in period one, then the additional consumption available in period two is the stochastic net return times the investment- the third term $\left(\mathbf{b}_{2}-r\right) \mathrm{I}_{1}$.

If the bad state of nature occurs $b_{2}=b_{2}{ }^{-}<r$ then the burden of the debt resulting from $\left(b^{-}-r\right) I_{1}$ could depress consumption $\mathrm{C}_{2}$ to an intolerable level. In that case, the country would default rather than accept the required reduced standard of living.

The constrained optimization decision is to select the controls: consumption $\mathrm{C}_{1}>$ 0 and investment $\mathrm{I}_{1} \geq 0$ during period one to maximize the expectation over the stochastic variable $\mathbf{b}_{2}$ of the discounted value of utility over the two periods. We assume a HARA utility function, $\mathrm{U}(\mathrm{C})=(1 / \gamma) \mathrm{C}^{\gamma}$, with positive risk aversion, $(1-\gamma)>0$. A special case that we use frequently is when $\gamma=0$, so that the utility function is $\operatorname{logarithmic} \mathrm{U}(\mathrm{C})=\log \mathrm{C}$. The great advantage of using the HARA function, particularly in the long-term model in chapter three is that one can solve for the optimal controls analytically. Otherwise, the optimal controls are solved numerically by using a computer.

An important constraint is that there should be no default. This means that consumption in period two, in the bad case, should exceed a minimum tolerable level $\mathrm{C}_{2}{ }^{-}$ $>\mathrm{C}_{\min } \geq 0$. 
The solution of the STCM models is the subject of chapter two. The conclusions are described in figure 1-1 below for the optimal debt/capital $\mathrm{f}=\mathrm{L}_{1} / \mathrm{K}_{1}$. We concentrate upon the logarithmic case, with risk aversion equal to unity. The results are clear in that case.

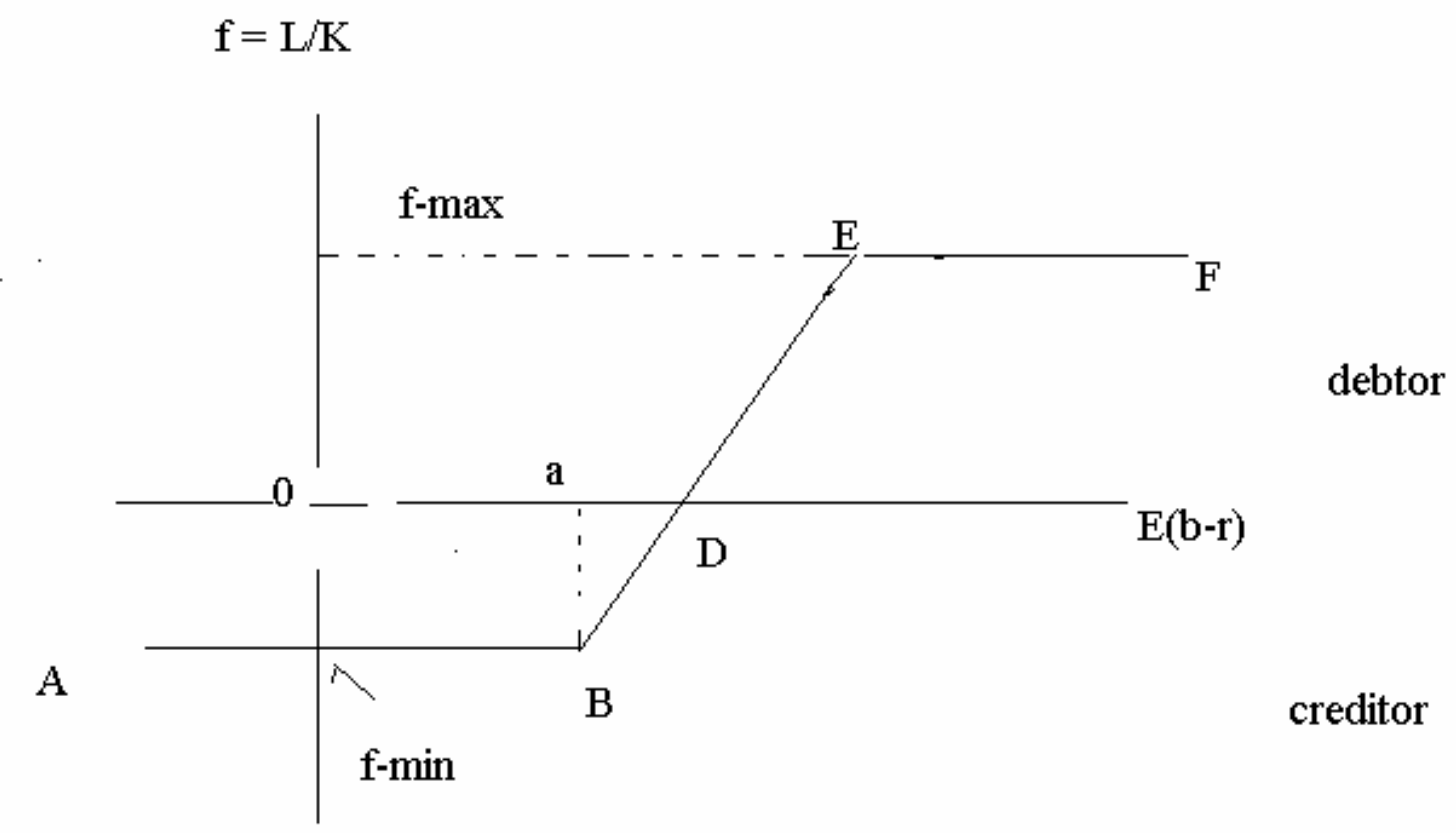

Optimal debt/capital $\mathrm{f}=\mathrm{L} / \mathrm{K}$

Figure 1-1. Optimal debt/capital $\mathrm{f}=\mathrm{L}_{1} / \mathrm{K}_{1}$ is curve $\mathrm{ABDEF}$. Expected net return $x=E(b-r)=\left[p b^{+}+(1-p) b^{-}\right]-r$. Along ABD the country is a creditor. Along DEF the country is a debtor. If debt/capital exceeds f-max, the probability of default is $(1-p)>0$.

Optimal saving/capital is a constant independent of the expected net return $\mathrm{x}=$ $\mathrm{E}(\mathrm{b}-\mathrm{r})$. Optimal investment/capital is zero for expected net return $x<a$ in figure 1. Risk premium $a$ is related to the ratio of the possible loss from investment in capital divided by the return if all wealth were invested abroad at the safe return. This means that, for $x<a$, the country will be a creditor and will invest all of its saving abroad earning the safe rate of return $r>0$. The debt/capital will be f-min $<0$, where the country is a creditor. 
When the expected net return rises above $a$, investment will be positive, thereby reducing the capital outflow. When the expected net return $x=D$, investment will equal saving and the country will neither be a creditor or a debtor. When $x>D$, then investment will exceed saving. There will be a short-term capital inflow and a positive optimal ratio of $\mathrm{f}=\mathrm{debt} /$ capital $>0$. The constraint that there be no default means that there is a maximal debt, $\mathrm{f}-\mathrm{max}$, such that in the event of a bad state of nature $b_{2}=b^{-}$, the level of consumption would exceed $\mathrm{C}_{\min }$.

\section{Summary:}

Curve $A B D E F$ is the constrained optimal ratio debt/capital, in the short-term capital flow model. Expected utility is maximized along this curve. Insofar as the debt deviates from the curve, expected utility is reduced. The optimal debt is a benchmark of

performance. Debt crises result because the actual debt deviates from the optimal debt. If the debt exceeds f-max, due to non-optimal behavior of the public and private sectors then: with probability $(1-p)>0$ consumption will be less than $\mathrm{C}_{\min }$ and there will be a default. Alternatively, the likelihood of default rises continuously as the utility of consumption $\mathrm{C}_{2}$ declines. In part 4 below, examples of Warning Signal are given for several emerging market countries.

\section{Dynamic Programming Optimization in long-term debt models}

For many countries the main obligations to foreigners arise from direct investment and portfolio investment. These forms of "debt" have no maturity date, but must be serviced regularly with interest and dividend payments. The modeling of optimal long-term debt in continuous time over an infinite horizon is very different from the modeling of short-term debt in discrete time described in part 2 above. The short-term debt model has a constraint that principal plus interest must be repaid at maturity. This is a model of repeating cycles of debt and repayment. If the debt exceeds debt-max due to non-optimal behavior of the public and private sectors, and the "bad" state of nature occurs, it may be impossible to satisfy this constraint with a positive consumption even if investment falls to the minimum. Then bankruptcy occurs. In the long-term debt model, there is no maturity date. Bankruptcy can only occur if net worth, to be defined below, is negative. The optimal controls will prevent that from occurring. 
Consumption and the growth of the debt are described by equations (1) and (2) above. The two sources of uncertainty are the productivity of capital and the real interest rate, which may be correlated. In section 3.1 the optimality criteria are discussed. In section 3.2 we describe two models with alternative stochastic processes concerning the sources of uncertainty: the Prototype Model and the Ergodic Mean Reversion Model. In section 3.3, we indicate why the literature that uses the "inter-temporal budget constraint" (IBC) is inadequate. Section (3.4) explains why and how we use the Dynamic Programming analysis. The conclusions concerning the optimal debt/net worth ratio, capital/net worth ratio and consumption/net worth are described in section (3.5). In part 4 we give an example of the implications of the DP analysis by providing Early Warning Signal of Argentine crisis of 2000-2001. In part 7, we give an example of the interaction of an overvalued currency and excess debt in producing the crisis in Thailand 1997-98.

\subsection{Optimality Criteria}

Several reasonable optimality criteria are used in the mathematical finance literature. Usually the criterion is to select the control/decision variables, consumption, debt or capital subject to constraints, to maximize the expectation (E) of the discounted value of a concave utility of consumption $\mathrm{U}\left(\mathrm{C}_{\mathrm{t}}\right)$ over an horizon $(0, \mathrm{~T})$, where $\mathrm{T}$ may be infinite or finite. These are equations (4a) or (4b). In the infinite horizon case, the discount rate is $\delta \geq 0$. The expectation is taken over the stochastic variables: the productivity of capital and real rate of interest.

Analytic solutions of the dynamic programming equation can be obtained if the utility function is HARA $^{10}$ described in equations (4a) and (4b). The coefficient of risk aversion is $(1-\gamma)>0$. The lower is $\gamma$, the greater is the risk aversion. Negative and zero values of $\gamma$ imply considerable aversion to risk. In the case where $\gamma \leq 0$, the utility of a zero consumption is minus infinity. When $\gamma=0$, the utility function is logarithmic.

$$
\begin{array}{lll}
\text { (4a) } J_{1}=E \int^{T} C_{t}^{\gamma} / \gamma e^{-\delta t} d t & \gamma \neq 0 & T>t>0 \\
\text { (4b) } J_{2}=E \int^{T} \ln C_{t} e^{-\delta t} d t & \gamma=0 & T>t>0
\end{array}
$$

\footnotetext{
${ }^{10}$ That is the reason that Merton used HARA. Otherwise, the DP equation must be solved numerically using a computer.
} 
Two constraints are imposed. (A) Consumption is always positive. (B) Net worth must always be positive. Define net worth $\mathrm{X}_{\mathrm{t}}>0$ as "capital" less debt. A negative debt is a financial asset. Unless constraint (B) is imposed, Ponzi schemes are possible: borrow to finance consumption and borrow more to service the debt. In that case, capital does not grow. As the debt continues to grow exponentially, net worth will be driven to negative values. The constraint that net worth is always positive precludes Ponzi schemes.

There are two subjective variables, the discount rate and risk aversion. The discount rate is just another way of specifying the length of the horizon. A high discount rate places the emphasis upon what occurs in the near future, and essentially disregards the far future. A discount rate $\delta>0$ is necessary to derive a finite optimum over an infinite horizon if $\gamma \geq 0$, whereas if $\gamma<0$, then a discount rate is not necessary to derive a finite optimum over an infinite horizon.

Whenever the utility function is logarithmic, the optimal ratio of consumption/net worth equals the "discount rate". Consumption is social consumption, government plus private consumption expenditure. Low taxes and high government expenditures raise social consumption. Since the discount rate is arbitrary, this quantity can rationalize any social consumption policy. If populist policies lead to a high rate of social consumption/GDP, it can be "rationalized" as optimal policy with a high discount rate. Weight the present highly relative to the future. If the dictator, a Chairman Mao, follows policies that depress social consumption, it can be "rationalized" as optimal policy with a low discount rate. Weight the future highly relative to the present.

Criterion $\mathrm{J}_{3}$ in equation (5) does not involve the arbitrary discount rate. Quantity $\mathrm{J}_{3}$ is the expected growth rate of net worth over a horizon of length $\mathrm{T}$, given any constant ratio c of consumption to net worth, $\mathrm{C}_{\mathrm{t}} / \mathrm{X}_{\mathrm{t}}=\mathrm{c}>0$. Since consumption is a constant fraction of net worth the maximization of $J_{3}$ is the same as the maximization of the growth rate of consumption from an arbitrary initial level.

$$
\text { (5) } \begin{aligned}
J_{3}= & (1 / T) E\left[\ln X_{T} / X \mid C_{t} / X_{t}=c>0\right] \\
& =(1 / T) E\left[\ln C_{t} / C \mid C_{t} / X_{t}=c>0\right], \quad \mathrm{X}=\mathrm{X}(0), \mathrm{C}=\mathrm{C}(0)
\end{aligned}
$$

Criteria $\mathrm{J}_{1}$ and $\mathrm{J}_{2}$ allow us to solve for both the optimum debt/net worth ratio, capital/net worth and the optimum consumption/net worth, whereas criterion $\mathrm{J}_{3}$ only allows us to solve for the optimal debt/net worth and capital/net worth. We explain in 
chapter three that the same optimal ratios of debt/net worth and capital/net worth are obtained whether we use criterion $\mathrm{J}_{2}$ or $\mathrm{J}_{3}$.

There is another criterion, which reflects extreme aversion to risk. The consumption in any period depends upon both the controls/decision variables consumption, capital or debt - and the stochastic productivity of capital. Suppose that there is a finite set of productivities of capital and a corresponding likelihood function. The Max-min criterion of optimality is to select the controls that maximize the minimum expected values of consumption for very large values of risk aversion. Fleming (2005) analyzes this very conservative case.

\subsection{Stochastic Processes}

The sources of uncertainty are modeled as stochastic processes in continuous time. The prototype model assumes that both the productivity of capital $b_{t}$ and the world real rate of interest $r_{t}$ can be described by statistical functions such as Brownian motion ${ }^{11}$ with drift. The mean return on investment is $b$, but there is no mean reversion. The change in the return to investment from one "period" to the next is purely random with a zero expectation, Brownian motion. Similarly, there is a world real rate of interest at which the country can borrow or lend. The mean is $r$, but there is no mean reversion. The change in the real rate of interest from one "period" to the next is just the Brownian motion with drift.

An alternative stochastic process is that the productivity of capital is still Brownian Motion with drift but that the world real interest rate, dependent upon a large vector of factors, is described by Ergodic Mean Reversion. This stochastic process is described by the Ornstein-Uhlenbeck equation, which states that the change in the real rate of interest from one "period" to the next is not completely random. One part is a reversion to the mean, and the second part is Brownian motion. The net result is that the real rate of interest is normally distributed and converges to a distribution whose mean is $r$ with a positive variance. The stochastic processes in the two models are summarized.

\footnotetext{
${ }^{11}$ A Brownian motion process has independent increments that are normally distributed. The expectation is zero and the variance is directly related to the length of the period.
} 
$\underline{\text { Return on investment } \mathrm{b}_{\mathrm{t}}}$

Prototype model

Ergodic mean reversion
Brownian motion with drift

Brownian motion with drift $\underline{\text { real interest rate } r_{t}}$

Brownian motion with drift

Ornstein-Uhlenbeck

Mathematically, it is easy to reverse which variable is described by Brownian motion with drift, and which is described by Ergodic Mean Reversion. In any empirical application to determine the optimal debt ratio, we first examine what are the appropriate stochastic processes for each variable: the return on investment and the real rate of interest. In chapter three, we compare the optimal debt ratio in each of the two models: Prototype and Ergodic Mean Reversion.

\subsection{Inter-temporal Optimization: Stochastic Optimal Control, Dynamic Programming}

The standard approach in the economics literature concerning inter-temporal optimization $^{12}$ is to maximize the expectation of the discounted value of the utility of consumption subject to an "Inter-temporal Budget Constraint" IBC. The inter-temporal case is treated as the analogue of the standard deterministic case of consumer choice. In the timeless case, the consumer has a utility function over a vector of goods, leisure and services whose prices are given and the consumer has a fixed amount of resources, money and time. The constraint is that the choice is restricted to the amount of resources available. The budget constraint is known with certainty since prices and resources available are known when the choice is made. The IBC is of an entirely different nature. The object of an "inter-temporal budget constraint" is to prevent a "free lunch", or engage in a Ponzi scheme where debts are never repaid. The IBC imposed is a terminal condition. At finite date $\mathrm{T}>0$ the debts are cleared, debt $\mathrm{L}_{\mathrm{T}}=0$. The IBC is inappropriate in a stochastic environment/a world of uncertainty. Instead, one must use the techniques of stochastic optimal control/dynamic programming.

From equation (1), the debt $\mathrm{L}_{\mathrm{T}}$ at time $\mathrm{T}$ is the initial debt $\mathrm{L}(0)$ plus the sum of the excess of expenditures for consumption $C_{t}$ plus investment $I_{t}$ plus interest on the debt $r_{t} L_{t}$ less Gross Domestic Product $Y_{t}$. The IBC is that the debt is paid off at the terminal date. The condition that $\mathrm{L}_{T}=0$ implies the $\mathbf{I B C}$, the sum of absorption $\left(\mathrm{C}_{t}+\mathrm{I}_{t}\right)$ is equal to the sum of the Gross National Product $\left(\mathbf{Y}_{\mathbf{t}}-\mathbf{r}_{\mathbf{t}} \mathrm{L}_{\mathbf{t}}\right)$.

\footnotetext{
${ }^{12}$ A discussion of this literature is in Gandolfo and Turnovsky.
} 
The stochastic variables (in bold letters) are $\mathbf{Y}_{\mathrm{t}}$ the real GDP and $\mathbf{r}_{\mathrm{t}}$ the real interest rate. Given the uncertainty concerning the productivity of capital and real interest rate, the future is unpredictable. At any time $\mathrm{s}<\mathrm{T}$ when the debt is $\mathrm{L}_{\mathrm{s}}$, how can anyone know if any country will/will not be, violating the IBC?

The IBC is unknowable, unenforceable and is a non-operational concept. If a country has a debt L(0) at the present, how can one know if the IBC will be satisfied even if a given policy - a sequence of investment and consumption - is followed? The reason is that $\mathbf{Y}_{\mathrm{t}}, \mathbf{r}_{\mathrm{t}}$ the real GDP and interest rate are stochastic variables with Brownian Motion components. For example, when the price of oil (during the oil crises periods) was high the oil producing countries and the oil importing countries expected it to continue. In the former huge investment and consumption projects were undertaken in the expectation that the real GDP would remain high. In the oil consuming countries, costly energy saving policies were imposed. These anticipations did not materialize and the oil producing countries were saddled with large debts.

This profound deficiency of the IBC approach led Fleming and Stein ${ }^{13}$ to use dynamic programming DP approach ${ }^{14}$, which features prominently in this book.

\subsection{The Dynamic Programming DP/Stochastic Optimal Control Approach SOC ${ }^{15}$}

Our underlying models are Markov diffusion processes where the future evolution of the system depends upon the present state and not at all upon the paths leading up to the present state. For example, the change in the debt $\mathrm{dL}_{\mathrm{t}}$ in equation (1) depends upon the current values of the gross domestic product $Y_{t}$, consumption, investment, real interest rate $r_{t}$ and debt $L_{t}$, and not upon what factors in the past produced the current debt or gross domestic product.

The system is stochastic, unpredictable. Even if one specified the controls/decisions ${ }^{16}$ from the present to any future date, the future is unpredictable

\footnotetext{
${ }^{13}$ Fleming and Stein (2004), Fleming (2004) and Stein (2004).

14 The seminal work was by Bellman The DP approach is generally used in the mathematical finance literature, starting from the work of Robert Merton.

${ }^{15}$ This section is an intuitive discussion of chapter three, which is based upon techniques used in the mathematical finance literature.

${ }^{16}$ Controls and decisions are used interchangeably.
} 
because there are many paths that the system can take due to the stochastic processes describing the real GDP and the real interest rate. At each instant of time the "controller/decision maker" knows the state of the system, and only has information up to the present. Since, the controller cannot anticipate the future, the DP approach involves a multi-stage decision process. The principle of optimality of DP is that: whatever the initial state and the initial decisions are, the remaining decisions must constitute an optimal policy with regard to the state resulting from the first decision. In a stochastic system, the optimal controls selected at any time depend upon the current information available and enter as feedback functions of the currently observable state. This is very different from the IBC approach.

The state variable in the stochastic systems discussed in this book is net worth $X_{t}$ defined as "capital" $\mathrm{K}_{\mathrm{t}}$ less debt $\mathrm{L}_{\mathrm{t}}$. The change in capital is investment over the period, and the change in the debt is equation (1). The latter involves the stochastic variables, the productivity of capital and the real rate of interest.

The DP solutions of the optimization of the expected discounted value of utility $\left(\mathrm{J}_{1}, \mathrm{~J}_{2}\right.$ in equations $\left.4 \mathrm{a}, 4 \mathrm{~b}\right)$ given the dynamical system concerning net worth involve the Hamilton-Jacobi-Bellman (HJB) equation discussed in chapter three. The DP analysis of inter-temporal optimization is quite technical, however the optimal debt/net worth $\mathrm{f}$ in the HJB equation can be explained in terms of the well known Tobin Mean-Variance $\mathbf{M - V}$ model.

The optimal debt/net worth $\mathrm{f}$ in the HJB equation is chosen to maximize $\mathrm{W}$ in equation (6).

(6) $W=\max _{f}[$ Mean - (risk aversion) Risk].

The Mean term $M(f, c)$ is a linear function of the debt ratio and the consumption ratio. It is the percentage change in net worth ${ }^{17}$ if there were no uncertainty. Risk is $R(f)$ and $(1-\gamma)$ is risk aversion. The risk term concerns the variance of the percent change in net worth. In the logarithmic cases $(\gamma=0)$, risk aversion is unity. Term $R(f)$ contains the variances of the productivity of capital, the interest rate and their correlation. Stochastic term $\mathrm{R}(\mathrm{f})$ is a quadratic function of the debt ratio. A unique optimal ratio of debt/net worth is derived that maximizes $\mathrm{W}$, which can be interpreted as $\mathrm{M}-\mathrm{V}$ expected utility. A

\footnotetext{
${ }^{17}$ This is $\mathrm{dX} / \mathrm{X}$ but it is not the growth rate, which is the percentage change per unit of time.
} 
graphical explanation of equation (6) presented in chapter three provides the intuition behind the DP results.

\subsection{Implications of the DP solution of the long-term capital model}

The Stochastic Optimal Control/Dynamic Programming analysis is used to derive the inter-temporal optimal conditions. The debt/net worth ratio $\mathrm{f}_{\mathrm{t}}=\mathrm{L}_{\mathrm{t}} / \mathrm{X}_{\mathrm{t}}=\mathrm{f}^{*}$ that maximizes performance criterion $\mathrm{J}_{1}$, equation ( $4 \mathrm{a}$ ) is the one that maximizes equation $\mathrm{W}$ in (6). The derived optimal debt in equation (7) is a benchmark measure of performance in a stochastic environment. Net worth is capital less debt. Therefore, the optimal ratio $\mathrm{k}^{*}$ of capital/net worth is $\mathrm{k}^{*}=\mathrm{f}^{*}+1$. In the logarithmic case $\mathrm{J}_{2}$ equation (4b) where risk aversion $(1-\gamma)=1$, the optimum debt/net worth is:

(7) $f^{*}=(b-r) / \sigma^{2}+f(0), \quad \sigma^{2}=\operatorname{var}\left(b_{t}-r_{t}\right)$.

Several crucial variables are in this equation. First, variable $b$ is the mean productivity of capital or return on investment, $r$ is mean real interest rate. In the $\operatorname{logarithmic}$ cases $\mathrm{J}_{2}$ and $\mathrm{J}_{3}$ risk aversion $(1-\gamma)=1$. Variable $\sigma^{2}$ is the variance of the quantity $\left(b_{t}-r_{t}\right)$, the current productivity of capital less the current interest rate, so that it also contains a covariance term. The intercept $f(0)$ is the optimal ratio of debt/net worth that minimizes risk. When the correlation coefficient between the growth rate and interest rate is less than $\sigma_{y} / \sigma_{r}$, the intercept $f(0)$ is negative. The optimum debt ratio $\mathrm{f}^{*}$ in the Prototype model is equation (7), which is our benchmark of performance. Equation (7) is graphed in Figure 1-2 as line $U-S$. The debt ratio $f=L / X$ is plotted on the ordinate and the risk adjusted mean net rate of return $\mathrm{z}=(b-r) / \sigma^{2}$ is plotted on the abscissa 


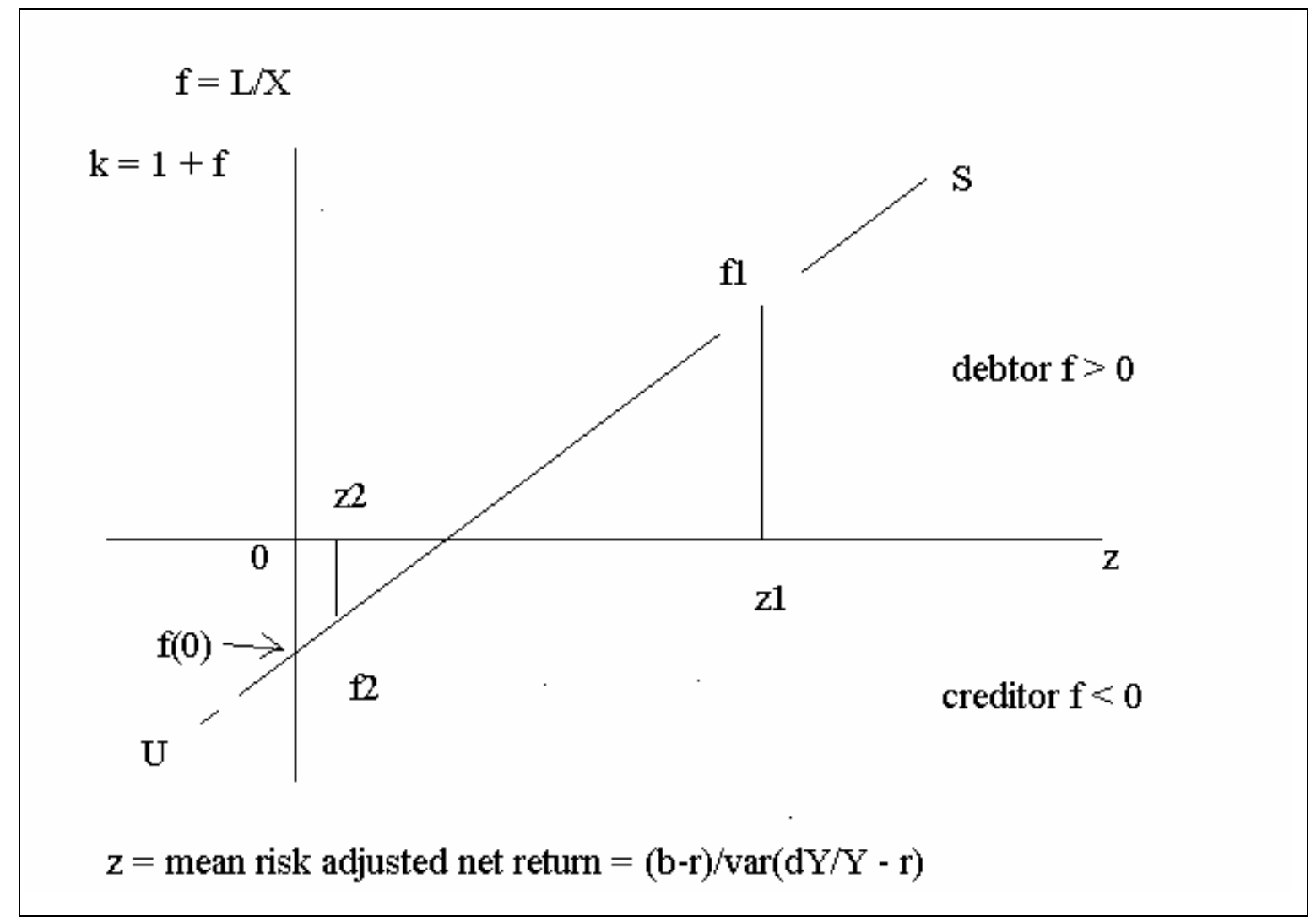

Figure 1-2. Optimal Ratio Debt/Net Worth $f^{*}$ is line U-S, when risk aversion is unity. In the Prototype model, the risk adjusted net return $\mathrm{z}=(\mathrm{b}-\mathrm{r}) / \sigma^{2}, \sigma^{2}=\operatorname{var}\left(\mathrm{b}_{\mathrm{t}}-\mathrm{r}_{\mathrm{t}}\right)$. In the Ergodic Mean Reversion model the adjusted net return $\mathrm{z}=\left(\mathrm{b}-\mathrm{r}_{\mathrm{t}}\right) / \mathrm{var} \mathrm{b}_{\mathrm{t}}$. Variance $\mathrm{b}_{\mathrm{t}}$ and var $y_{t}$ are used interchangeably, since $b=Y / K$. Optimal capital/net worth $k^{*}=1+\mathrm{f}^{*}$.

\section{Summary and implications of the DP analysis ${ }^{18}$}

(i) Consider two countries, which differ greatly in terms of wealth and income. There is no necessary relation between per capital wealth and the risk adjusted mean net return $\mathrm{z}=(b-r) / \sigma^{2}$. In rich/developed country $\mathrm{I}$, the risk adjusted mean net return $\mathrm{z}=\mathrm{z}_{1}$ and in poor/emerging market country II the risk adjusted mean net return $\mathrm{z}=\mathrm{z}_{2}$. In the situation described in figure 1-2, it is optimal that the poor country should be a creditor of the rich country because the mean return per unit of risk $\mathrm{z}=(b-r) / \sigma^{2}$ is higher in the rich country. Either the mean net return $(b-r)$ is higher or the risk $\sigma^{2}$ is lower in rich country I than in poor country II.

\footnotetext{
${ }^{18}$ These propositions refer to the case where risk aversion $(1-\gamma)$ is unity, the logarithmic case.
} 
(ii) The expected growth of net worth is maximal, for any consumption ratio, when the debt/net worth ratio ${ }^{19}$ is optimal at $\mathrm{f}^{*}$. As the debt ratio rises above the line U-S which describes the optimum $f^{*}$, the expected growth rate declines, and the risk - the variance of the growth rate - increases.

(iii) Objective measures of vulnerability to external shocks are implied by the analysis. Vulnerability is taken as a situation where, if the debt is to be serviced, consumption must be reduced when there are external shocks. Say that consumption is a constant proportion of net worth. This proportion may or may not be "optimal". As the actual debt ratio rises above the optimum, say because non-optimal policies are undertaken by the public sector, the expected growth rates of net worth and consumption decline and their variances rise. Therefore, the vulnerability to shocks increases continuously as f rises relative to $\mathrm{f}^{*}$. The probability of a decline in consumption rises and the probability of a debt crisis increases continuously as the debt ratio exceeds the optimum.

(iv) The level of the ratio ${ }^{20}$ of debt/GDP per se is not a relevant variable in producing a crisis. Instead it is the excess of the actual debt ratio over the optimal $\mathrm{f}^{*}$ that raises the probability of a crisis. A Warning Signal $\Psi t=\left(f_{t}-f^{*}\right)$, based upon available information, is that the debt ratio is rising above line U-S in figure 1-2. When the mean net return per unit of risk $\mathrm{z}=(b-r) / \sigma^{2}$ is falling, the optimal debt ratio should be declining. If, however, the debt/GDP ratio is rising because non-optimal policies are followed, it is more probable that the debt ratio lies in the region above the curve US.

In the Ergodic Mean Reversion (EMR) model, suppose that the aim is to maximize the expected growth rate of consumption, given an arbitrary ratio of consumption/net worth. This is the maximization of $\mathrm{J}_{3}$ in equation (5). The ratio of the optimal debt/net worth ratio $\mathrm{f}^{* *}$ is $(7 \mathrm{a})$, when the disturbances to the productivity of capital and interest rate are independent, $\rho=0$.

(7a) $f^{* *}=\left(b-r_{t}\right) / \sigma_{y}^{2}-1 . \quad$ EMR

\footnotetext{
19 The ratio of capital/net worth is equal to 1 plus the debt ratio.

${ }^{20}$ The ratio of $h=\mathrm{debt} / \mathrm{GDP}$ is positively related to the ratio $f^{*}=\mathrm{debt} /$ net worth. The equation is: $h=(1 / b) f /(1+f)$, where $b$ is the mean productivity of investment. Therefore, one can speak of the ratios $f$ and $h$ interchangeably
} 
The main difference between the optimal debt ratio in (7a) for the EMR and equation (7) for the Prototype Model is that: in the Prototype model equation (7), the risk adjusted return $\mathrm{z}$ is the mean net return (b-r) divided by the total variance of the return $\sigma^{2}$ $=\operatorname{var}\left(b_{t}-r_{t}\right)$. In the Ergodic Mean Reversion model, the adjusted return $z=z_{t}$ is the mean return on capital less the current rate of interest $\left(b-r_{t}\right)$ divided by the variance $\sigma_{b}{ }^{2}$ $=\sigma_{y}{ }^{2}$ of the return on capital. Therefore, figure 1-2 can be used to describe the optimal debt ratio in either model; however, the risk adjusted return must be suitably interpreted.

\section{Examples of Early Warning Signals EWS of Debt Crises}

The operational conclusions from the two models are used to derive EWS of debt crises. They occur primarily because the government policies lead to non-optimal saving and investment. In section 4.1 we give examples based upon panel data ${ }^{21}$ of default risk in emerging market countries during the period 1979-2001. Section 4.2 contrasts Mexico that defaulted with Tunisia that did not. In section 4.3, the example is Argentina, which went from the darling of the creditors to the world's greatest defaulter. The main conclusion from the models developed in parts 2 and 3 are as follows.

- The debt/GDP ratio per se is not the relevant variable.

- The optimal debt ratio is described by the curve A-B-D-E-F in figure 1-1 for the short-term debt model, and by line U-S in figure 1-2 in the long-term debt model.

- The greater is the deviation of the actual debt from the optimal debt, the greater is the probability of default in the event of "bad" external shocks. In the short-term debt model figure 1-1, if the debt exceeds debt-max, then the default is likely with probability (1-p).

- The optimal debt/net worth ratio $\mathrm{f}^{*}$ in the long-term debt model has the form: $\mathrm{f}_{\mathrm{t}}$ * $=a z_{t}+\mathrm{f}(0)$, where $\mathrm{z}_{\mathrm{t}}$ is the risk adjusted net return $(\mathrm{b}-\mathrm{r}) / \sigma^{2}, f(0)$ is a constant and $a$ is the reciprocal of risk aversion.

- The EWS is that the actual debt ratio $\mathrm{f}_{\mathrm{t}}$ is deviating from the optimal $\mathrm{f}^{*}$.

\footnotetext{
${ }^{21}$ These examples are taken from chapter five
} 


\subsection{Emerging Markets: panel data}

Emerging market countries during the period 1979-2001 were divided into two groups: those that defaulted/renegotiated their debts with either official or private creditors $^{22}$ and those that did not. The relation between the debt/GDP ratio and the expected net return did not accord with the optimal ratio in figures 1-1 or 1-2 in either set of countries examined (renegotiate/no-default). The main difference between the two groups concerned the excess debt, $\omega=\left(f-f_{\max }\right)$, the deviation between the actual $\mathrm{debt} / \mathrm{GDP}$ ratio from the maximal debt/GDP ratio. When there is an excess debt, the economy is vulnerable. In the event of a bad shock, the level of consumption would fall below the minimum and would default. The bad shock will occur with probability (1-p).

In the empirical applications of the short-term capital model to emerging markets, a Warning Signal $\omega=\left(f-f_{\text {max }}\right)$ is equation (8). It is a "flashing red" Warning Signal of a debt crisis. The actual debt ratio is $f_{t}$, the ratio of investment/GDP is $j$, the mean return on investment is $b_{1}$, the return on investment in the bad case is $b_{2}^{-}$and the rate of interest is $r$. (8) $\omega_{t}=f_{t}-f_{\max }=f_{t}-\left[\left(b_{2}^{-} / b_{1}\right)+\left(1+b_{2}^{-}\right) j\right](1+r)$.

Default is often a political decision, where international organizations and foreign countries are directly involved in bailouts. In the absence of bailouts, the excess debt is a sufficient condition for default. Our results based upon panel data were that:

In the cases where the debt was rescheduled/defaulted, the excess debt was positive in $84 \%$ of the cases. In the cases where there was no reschedule/default, the excess debt was positive in $47 \%$ of the cases.

\subsection{Mexico and Tunisia}

Mexico defaulted to official and to private creditors during the period 1983-96, whereas Tunisia did not. The optimal debt/net worth ratio $f^{*}$ has the form: $f_{t}^{*}=a z_{t}+f(0)$, where $\mathrm{z}_{\mathrm{t}}$ is the risk adjusted net return $(\mathrm{b}-\mathrm{r}) / \sigma^{2}, f(0)$ is a constant, which is almost always negative, and $a$ is the reciprocal of risk aversion. This equation applies to all of the models, suitably interpreted according to the equation in parts 2 and 3 above. Excess debt

\footnotetext{
${ }^{22}$ Define default/renegotiation as a condition where the scheduled debt service is not paid on the due date under the original contracted conditions.
} 
is $\Psi_{t}=f_{t}-f^{*}=f_{t}-\left(\mathrm{az}_{\mathrm{t}}+\mathrm{f}(0)\right)$. Table 1 describes the relevant data from which one can infer that there was an excess debt in Mexico and not in Tunisia.

Table 1. Mexico and Tunisia 1979 - 2001

\begin{tabular}{|l|l|l|}
\hline Variable & Mexico - default & Tunisia - no default \\
\hline Debt/GDP f & 0.45 & 0.61 \\
\hline Mean net return $(b-r)$ & 0.057 & 0.107 \\
\hline Variance of net return $\sigma^{2}$ & $(.16)^{2}$ & $(.09)^{2}$ \\
\hline $\mathrm{z}=(\mathrm{b}-\mathrm{r}) / \sigma^{2}$ & 2.23 & 13.21 \\
\hline $\begin{array}{l}\text { Optimal } \mathrm{f}_{\mathrm{t}}^{*}=\mathrm{az}_{\mathrm{t}}+\mathrm{f}(0), \\
\mathrm{f}(0)<0, \mathrm{a}=1 /(1-\gamma)\end{array}$ & $\mathrm{a}(2.23)+\mathrm{f}(0)$ & $\mathrm{a}(13.21)+\mathrm{f}(0)$ \\
\hline$\omega=\mathrm{f}-\left(\mathrm{f}_{\max }\right)$ & 0.322 & -0.116 \\
\hline$\Psi=\mathrm{f}-(\mathrm{az}+\mathrm{f}(0))$ & $0.45-(2.23 \mathrm{a}+\mathrm{f}(0))$ & $.61-(13.2 \mathrm{a}+\mathrm{f}(0))$ \\
\hline
\end{tabular}

Compare table 1 with the conclusions marked by bullets above. First: Tunisia, which did not default, had a higher debt ratio than did Mexico, which defaulted. Second: assuming that the constant $f(0)<0$ was relatively similar in both countries, the risk adjusted net return z was very much higher in Tunisia. For any coefficient of risk aversion, the optimal debt ratio should be much higher in Tunisia than in Mexico. Alternatively, if the debt ratio in Tunisia was close to the optimal $\mathrm{f}_{\mathrm{t}} *=a z_{\mathrm{t}}+\mathrm{f}(0)$, described line U-S, the Mexican debt ratio was far above the line. See the last row in table 1. Third: the Mexican debt ratio was above the maximal debt in figure 1-1, defined in equation (8). The excess debt, which leads to a probability of default in the bad case, is $\omega$ in the next to last row. It is very large and positive. By contrast, Tunisia did not have an excess debt. The $\omega$ for Tunisia was negative; the debt ratio was below the debt-max level.

\subsection{Argentina: From Triumph to Defaults}

Severe crises result from an interaction between an excess debt and a misaligned exchange rate. Misaligned exchange rates are discussed in part 5. In the present section, we give an example of how we apply the SOC/DP analysis of excessive debt to 
Argentina that went from Triumph in the early 1990's to Tragedy in 2001. Warning Signals are obtained based upon available information. In part 7, we (i) compare our theoretically based EWS of currency and debt crises with the eclectic-econometric approach in the literature, and (ii) give an example of how the interaction between an overvalued exchange rate $\Phi>0$ and an excess debt $\Psi>0$ provided EWS of the 1997-98 crisis in Thailand.

Michael Mussa's (2002) retrospective description ${ }^{23}$, and the International Monetary Fund's Independent Evaluation Office Report (2004), of the Argentine crisis can be integrated with the SOC/DP analysis above. A new economic policy - the convertibility plan - was instituted in the spring of 1991 to deal with the hyperinflation that existed at the beginnings of the 1990s. The currency was pegged to the \$US and a currency board arrangement limited domestic money creation. This plan was successful. During the period 1993-98, the inflation rate was below 3\% and the growth rate was about $4 \%$ per annum. Whereas most of the miracle Asian economies collapsed into crisis from mid 1997 to early 1998, Argentina became the darling of the world credit market. It was able to float large issues of medium to long-term debt on the world credit markets at comparatively modest spreads over the US Treasuries.

Not only did the world credit markets and the International Monetary Fund applaud the Argentine policies, but also several academic economists viewed Argentina as a model of growth. Dornbusch (Lecture II: 1998) wrote: "A currency Board arrangement, a fixed exchange rate and a central bank that has no discretionary power over the money supply...is a very good system... One spectacularly successful case...is Argentina...the Argentine experience is the one that deserves most attention because, one, it has lasted, and two, it has been extremely successful as a cornerstone of reform in an economy, and three, it has produced an average growth of six per cent".

Barely a few years later in 2001, Argentina's decade long experiment ended in tragedy. The banking system was effectively closed at the beginning of December 2001, the exchange peg was gone, the peso was trading at substantially depreciated rate against the \$US. Argentina defaulted on its sovereign debt and was transformed within barely

\footnotetext{
${ }^{23}$ The description of the Argentine experience in this section often paraphrases Mussa's monograph.
} 
two years from the darling of the emerging market finance to "the world's leading deadbeat".

The reason why the financial markets, the International Monetary Fund and academic economists failed to anticipate the crisis was that their attention was focused upon the monetary sphere - since inflation is a monetary phenomenon - and not upon the external debt. The debt did not alarm them because the debt did not seem to be high relative to that prevailing in many industrial countries. A benchmark of an excessive debt was lacking. Our analysis implies that debt crises are not produced by the level of the debt/GDP but by the excess of the actual debt over the optimum debt ratio.

The fundamental causes of the disaster were the growth in social (public plus private) consumption and a fixed nominal exchange rate pegged to the \$US. The various levels of the Argentine governments succumbed to political pressures to spend significantly more than was raised by taxes. Much of the fiscal problems arose because the provinces retained the initiative for public spending, but the central government was ultimately responsible for raising revenues and servicing the debt. Since Argentina was thought of so highly by the financial markets, it was able to finance the excess spending by borrowing US dollars in the international markets at favorable interest rates.

An excess debt means that the debt ratio rises above the curve U-S in figure 1-2. In the Prototype model, the optimal debt ratio is equation (7) and in the Ergodic Mean Reversion model it is equation (7a). These equations are valid if the mean return is changing slowly relative to the Brownian Motion terms. A relatively general way of taking all of these factors into account is to graph the normalized variables. The normalized return to investment $b_{t}^{*}=\left[b_{t}-E(b)\right] / \sigma_{b}$ labeled B1_AR in figure 1-3. It is the deviation of the return from its longer-term mean per unit of risk ${ }^{24}$. The external SUS denominated debt/GDP, labeled DBTGDP_AR in figure 1-3, is also normalized. It is equal to the (debt/GDP - mean)/standard deviation. The debt ratio rose by two standard deviations from 1992-2001. However, the return on investment $b^{*}{ }_{t}$ was declining from 1997-2001.

The rise in the actual debt ratio and the decline in $b{ }_{t}$ the return/risk in figure 1-3 corresponds to a rise in the debt ratio above the curve U-S for the optimal debt ratio in

${ }^{24}$ This approach cancels the constant $\mathrm{f}(0)$ in equation (7). 
figure 1-2. An "excess debt" is generated. Insofar as there is an excess debt, the expected growth rate of GDP declines and its variance rises. The variance comes from the external shocks, which are disturbances to the productivity of capital (GDP/capital), the real rate of interest, and their correlation. Because of the non-optimal government policies, the Argentine economy became more vulnerable to shocks of the net return from its longerterm mean.

The major shock was the collapse of Brazil's crawling peg early in 1999, which led to a negative shock to the Argentine productivity of capital. When Argentina was forced to depreciate its currency- abandon the peg - the real rate of interest was positively shocked, because the debt was denominated in \$US. Consumption would have to be reduced, if Argentina was to service her debts. Confronted with this choice, Argentina defaulted.

Our conclusion is that there was an Early Warning Signal (EWS) of a sustained excessive debt, based upon available information. The debt ratio per se is not an EWS, whereas the excess debt $\Psi=\mathrm{f}-(\mathrm{az}+\mathrm{f}(0))$ is an EWS of a debt problem/crisis/default/ renegotiation. Theoretically this is the movement of the debt ratio above the curve US, and empirically it is that $b_{t}^{*}=\left(\mathrm{b}_{\mathrm{t}}-\right.$ mean $) / \mathrm{st}$. dev is falling significantly but the debt/GDP ratio is rising significantly for a period of years. This approach allows for gradual structural change in the productivity of capital. Another aspect of the crisis is a misaligned exchange rate, relative to the NATREX equilibrium exchange rate discussed in the next section, $\Phi_{t}>0$. An example of the interaction between excess debt and misaligned exchange rates is the provided in part 7 concerning the crisis in Thailand 1997-98. 


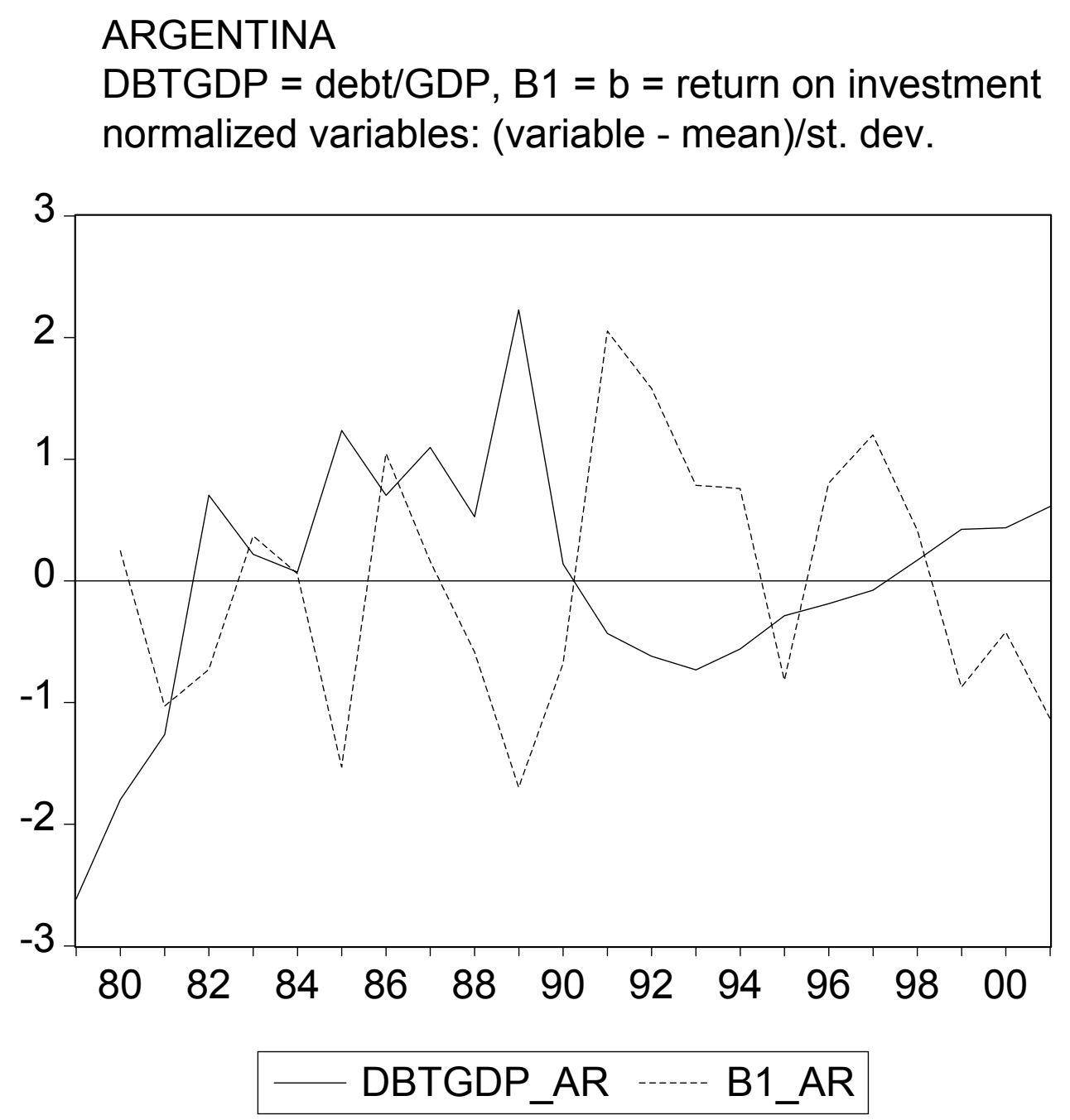

Figure 1-3. Debt/GDP (DBTGDP_AR) normalized, return on investment per unit of risk $\left(B 1 \_A R\right)=\left(b_{t}-\right.$ mean $) /$ st. dev. 


\section{Equilibrium Exchange Rates and Misalignment}

The optimal debt ratio $\mathrm{f}^{*}$ developed in the previous sections is a normative concept, according to the criteria discussed in section (3.1) above. The evolution of the actual debt ratio $\mathrm{F}_{\mathrm{t}}=\mathrm{L}_{\mathrm{t}} / \mathrm{Y}_{\mathrm{t}}$ results from decisions made by the private and public sectors, which may be far from optimal.

The actual external debt $\mathrm{L}_{\mathrm{t}}$, net liabilities to foreigners, grows insofar as absorption $\mathrm{A}_{t}$ of resources (consumption plus investment) by the private and public sectors exceeds the Gross National Product $\left(G N P=Y_{t}-r_{t} L_{t}\right)$. Equation (9) is the change in the debt/GDP, which can be expressed in three equivalent ways. The first part stresses absorption plus debt service, the second part stresses the current account deficit $\left(r_{t} L_{t}-B_{t}\right)$, and the third part stresses investment less saving.

(9) $\mathrm{dL}_{\mathrm{t}} / \mathrm{Y}_{\mathrm{t}}=\left[\left(\mathrm{A}_{\mathrm{t}} / \mathrm{Y}_{\mathrm{t}}\right)-1\right]+\mathrm{r}_{\mathrm{t}}\left(\mathrm{L}_{\mathrm{t}} / \mathrm{Y}_{\mathrm{t}}\right)=\left(\mathrm{r}_{\mathrm{t}} \mathrm{L}_{\mathrm{t}}-\mathrm{B}_{\mathrm{t}}\right)=\left(\mathrm{I}_{\mathrm{t}}-\mathrm{S}_{\mathrm{t}}\right), \mathrm{Y}_{\mathrm{t}}=\mathrm{GDP}$

$\mathrm{F}_{\mathrm{t}}=\mathrm{L}_{\mathrm{t}} / \mathrm{Y}_{\mathrm{t}},\left(\mathrm{I}_{\mathrm{t}}-\mathrm{S}_{\mathrm{t}}\right)=($ investment/GDP $)-($ saving/GDP $), \mathrm{B}=$ trade balance/GDP

For example ${ }^{25}$, since unification the eastern part of Germany absorbed more than the GDP; hence there were current account deficits $\left(r_{t} L_{t}-B_{t}\right)>0$. In 1997, public transfer payments from west to east were about one-third of the eastern German value added. These net transfers took up $4.25 \%$ of the West German GDP. Most of the transfers financed consumption. Social security benefits amounted to almost two-thirds of all attributable public transfers to eastern Germany, subsidies made up over one-tenth of these transfers, whereas about one-quarter was for investment purposes ${ }^{26}$.

As long as the Western Germans are willing to tolerate this situation, the Eastern Germans can maintain their excess absorption, excess of total investment less total saving or balance of payments deficit. Countries in Central and Eastern Europe CEEC are joining the European Union and eventually the Euro area. If absorption by the CEEC exceeds their GDP, they continue to run current account deficits, and their external debt $\mathrm{L}_{t}$ will grow according to equation (9). It is most unlikely that the other members of the European Community would finance their deficits. Then the CEEC would have to

\footnotetext{
${ }^{25}$ Deutsche Bundesbank, "Economic Conditions in eastern Germany", Monthly Report, April 1998.

${ }^{26}$ Promotional credits and tax concessions for stimulating the investment activity of the east German economy are hardly recorded in these figures.
} 
evaluate whether the resulting debts are sustainable, that is whether they will be exceeding the optimal levels discussed above.

The real exchange rate is a crucial variable in determining the evolution of the external debt, $d L_{t}=r_{t} L_{t}-B_{t}$, because the real exchange rate $R_{t}$ is a basic determinant of the trade balance $\mathrm{B}_{\mathrm{t}}$. Conversely, the level of the debt is a basic determinant of the equilibrium exchange rate, as we shall show. Both the real exchange rate and the debt are endogenous variables in a dynamic system.

At any time the real exchange rate produces balance of payments equilibrium. It satisfies equation (10) by equating the supply of and demand for foreign exchange. The first set of terms concern the "equilibrium" elements, and the second term $\varepsilon_{\mathrm{t}}$ subsumes the disequilibrium elements. The "equilibrium" terms in square brackets, investment less saving plus the current account, are conditional upon real economic fundamentals to be discussed shortly. Equilibrium requires that there is internal balance, where the rate of capacity utilization is at its longer term mean, and external balance where the real rates of interest at home and abroad are equal, there are neither changes in reserves, nor speculative capital flows. The second term $\varepsilon_{\mathrm{t}}$ contains the transitory or non-fundamental factors. The effects of speculative capital flows, cyclical factors and lags in adjustment of the trade balance to the exchange rate are subsumed under $\varepsilon_{\mathrm{t}}$.

(10) $\left[\left(\mathrm{I}_{\mathrm{t}}-\mathrm{S}_{\mathrm{t}}\right)+\mathrm{B}_{\mathrm{t}}-\mathrm{r}_{\mathrm{t}} \mathrm{F}_{\mathrm{t}}\right]+\varepsilon_{\mathrm{t}}=0, \quad \mathrm{E}\left(\varepsilon_{\mathrm{t}}\right)=0$

Medium run equilibrium satisfies equation (10) when $\varepsilon_{\mathrm{t}}=0$. Denote medium run equilibrium by $\mathrm{R}\left[\mathrm{F}_{\mathrm{t}} ; \mathrm{Z}_{\mathrm{t}}\right]$, where vector $\mathrm{Z}_{\mathrm{t}}$ consists of the real fundamentals underlying the saving, investment and trade balance functions. The medium run equilibrium is conditional upon the existing debt ratio, and evolves overtime as the debt ratio $F_{t}$ evolves. The crucial hypothesis is that the actual real exchange rate converges to a distribution whose mean is the equilibrium real exchange rate, but there is a considerable variance. The manner whereby the convergence occurs depends upon the exchange rate regime.

The dynamics of the $\mathrm{F}_{\mathrm{t}}=$ debt/GDP ratio is equation (11), derived from (9) and the growth rate $g$ of GDP. Since the real exchange rate affects the trade balance $B$, the evolution of the actual debt ratio is profoundly affected by the real exchange rate.

(11) $d F_{t} / d t=\left(I_{t}-S_{t}\right)-g_{t} F_{t}=\left(r_{t} F_{t}-B_{t}\right)-g_{t} F_{t}=\left(r_{t}-g_{t}\right) F_{t}-B_{t}$ 
In longer run equilibrium, the debt ratio stabilizes at a value that satisfies equation (12). The trade balance $B_{t}$ is sufficient to finance the interest plus dividend transfer on the debt net of growth $\left(\mathrm{r}_{\mathrm{t}}-\mathrm{g}_{\mathrm{t}}\right) \mathrm{F}_{\mathrm{t}}$. A negative debt is net foreign assets.

(12) $\left(\mathrm{r}_{\mathrm{t}}-\mathrm{g}_{\mathrm{t}}\right) \mathrm{F}_{\mathrm{t}}-\mathrm{B}_{\mathrm{t}}=0$.

Summary: The longer-run equilibrium real exchange rate $\mathrm{R}_{\mathrm{t}}{ }^{*}$ and debt/GDP ratio $\mathrm{F}_{\mathrm{t}}{ }^{*}$ satisfy both equation (10) when $\varepsilon_{\mathrm{t}}=0$, and equation (12). They are written as (13) and (14) to indicate that they both depend upon the real fundamentals $Z_{t}$. We call dynamic stock-flow model - consisting of equations (10) when $\varepsilon_{\mathrm{t}}=0$, (11)- (12) - the NATREX model, which is an acronym for the Natural Real Exchange Rate ${ }^{27}$.

(13) $\mathrm{R}_{\mathrm{t}}^{*}=\mathrm{R}\left(\mathrm{Z}_{\mathrm{t}}\right)$

(14) $\mathrm{F}_{\mathrm{t}}^{*}=\mathrm{F}\left(\mathrm{Z}_{\mathrm{t}}\right)$.

This is a model of positive economics and there is no presumption that the saving, investment and trade balance are optimal. The resulting equilibrium debt ratio is $\mathrm{F}^{*}$. For example, Populist governments (Argentina) pursue fiscal policies that raise the social consumption ratio above the discount rate of a "representative agent", or the Asian governments pursue monetary and subsidy policies that stimulate non-productive investment. The policies pursued in these cases lead to "equilibrium" debt ratios that were not optimal in the sense explained in parts 2 and 3.

The probability of a debt crisis is positively related to $\Psi_{\mathrm{t}}=\mathrm{F}^{*}{ }_{\mathrm{t}}-\mathrm{f}_{\mathrm{t}}$ the market equilibrium debt ratio $\mathrm{F}^{*}$ minus the optimal debt ratio $\mathrm{f}^{*}$ discussed earlier. We explain that exchange rate crises arise from exchange rate overvaluation, defined as the deviation of the actual from the equilibrium real exchange rate $\Phi_{t}=R_{t}-R\left(Z_{t}\right)>0$. There is an interaction between excess debt $\Psi_{\mathrm{t}}>0$ and overvalued exchange rates $\Phi_{\mathrm{t}}>0$. Therefore, the two types of crises are inter-related.

\subsection{Populist and Growth Scenarios}

The NATREX model is a technique of analysis that can be adapted to almost any situation and country ${ }^{28}$. The purpose of the model is to understand the effects of policies

\footnotetext{
${ }^{27}$ The NATREX appellation was suggested by Liliane Crouhy-Veyrac who compared the model to Wicksell's "natural" rate of interest.

${ }^{28}$ Allen explains the flexibility of this method of analysis.
} 
and external disturbances upon the trajectories of the equilibrium real exchange rate $R_{t}$ and equilibrium debt ratio $F_{t}$. The model specifies the equilibrium values $\left(R_{t}, F_{t}\right)$ which depend upon the vector of fundamentals $Z_{t}$. Insofar as the fundamentals vary over time, the equilibrium real exchange rate and debt ratio will vary over time, as indicated in equations (13) and (14). The equilibrium debt ratio in (14) is conditional upon the saving and investment decisions of the public plus private sectors. They may or may not be the optimal decisions derived on parts 2 and 3. Insofar as the "equilibrium" debt ratio $F_{t}=$ $F\left(Z_{t}\right)$ deviates from the optimal ratio $f^{*}$, the former is less sustainable.

The logic and insights of the NATREX model $^{29}$ can be summarized in two scenarios $^{30}$. Each scenario concerns different elements in the vector $Z_{t}$ of the fundamentals, and has different effects upon the equilibrium trajectories of the real exchange rate NATREX and of the external debt. NATREX analysis concerns the equilibrium real exchange rate and it is neither the actual real exchange rate nor the optimal exchange rate that would lead to the optimal debt ratio sketched in parts 2 and 3 . The core of the dynamic system relating the real exchange rate and the debt is equation (11).

The first scenario, called the Populist scenario, involves a decline in the ratio of social saving/GDP. This could occur when the government incurs high-employment budget deficits, lowers tax rates that raise consumption, or offers loan guarantees/subsidies for projects with low social returns. This represents rise in the consumption ratio/a decline in the saving ratio, a shift in the $\mathrm{S}$ function in equations (10) and (11). These Populist expenditures are designed to raise the standards of consumption/quality of life for the present generation.

The second scenario, called the Growth scenario, involves policies designed to raise the productivity of capital $b_{t}=Y_{t} / K_{t}$. Policies that come to mind involve the liberalization of the economy, increased competition, wage and price flexibility, the deregulation of financial markets, improved intermediation process between savers and

\footnotetext{
${ }^{29}$ The NATREX model is the subject of Stein, Allen et al $(1995,1997)$. It differs from Williamson's FEER model (1994) and from the behavioral econometric approach BEER of Clark and MacDonald (1999). See MacDonald and Stein (1999, ch. 1) and Driver and Westaway (2005) for a comparison of different approaches.

${ }^{30}$ A graphic and mathematical analysis of the scenarios is in chapter four. Here, we just present an intuitive explanation to prepare the reader for the technical analysis in the subsequent chapters.
} 
investors, and an honest and objective judicial system that enforces contracts. Growth policies improve the allocation of resources and bring the economy closer to the boundary of an expanding production possibility curve ${ }^{31}$.

Table 1 summarizes the differences between the two scenarios in the medium and the long run. The stories behind the dynamics are as follows.

The Populist scenario involves increases in social (public plus private) consumption relative to the GDP. External borrowing must finance the difference between investment and saving. The capital inflow appreciates the real exchange rate from initial level $\mathrm{R}(0)$ to medium run equilibrium $\mathrm{R}(1)$, where $\mathrm{T}=1$ denotes medium run equilibrium. The current account deficit is balanced by the capital inflow. The debt rises, since the current account deficit is the rate of change of the debt - equation (11). Current account deficits lead to growing transfer payments $\mathrm{r}_{\mathrm{t}} \mathrm{F}_{\mathrm{t}}$. This Populist scenario is potentially dynamically unstable because the increased debt raises the current account deficit, which then increases the debt further. The exchange rate depreciates, and the debt rises, steadily.

Stability can only occur if the rise in the debt, which lowers net worth equal to capital less debt, reduces social consumption/raises social saving. For example, the growing debt and depreciating exchange rate force the government to diminish the high employment budget deficit. Thereby, saving less investment rises. Long-run equilibrium (denoted by $\mathrm{T}=2$ ) is reached at a higher debt $\mathrm{F}(2)>\mathrm{F}(0)$ and a depreciated real exchange rate $\mathrm{R}(2)<\mathrm{R}(0)$. The longer-run depreciation of the exchange rate $\mathrm{R}(2)<\mathrm{R}(0)$ can be understood from equation (12). The debt is higher than initially. Therefore, the trade balance $\mathrm{B}(2)$ must be higher than initially to generate the foreign exchange to service the higher transfers ${ }^{32} r_{t} F(2)$. The real exchange rate must depreciate to $R(2)<$ $\mathrm{R}(0)$ in order to raise the trade balance to $\mathrm{B}(2)$.

The top half of table 2 summarizes the Populist scenario in the medium-run $(\mathrm{T}=$ $1)$ and the longer-run $(T=2)$. The rise in the debt is monotonic from $F(0)$ to $F(2)$. The

\footnotetext{
${ }^{31}$ To be sure, there will be short-run adverse effects as unprofitable enterprises are closed. The net effect in the shorter-run is to reduce employment and raise productivity. In the medium run, both productivity and employment grow.

${ }^{32}$ The interest rate must exceed the growth rate if the expected present value of future income is finite.
} 
trajectory of the real exchange rate is not monotonic. It first rises to $R(1)>R(0)$, and then falls to an equilibrium level $\mathrm{R}(2)<\mathrm{R}(0)$.

\section{Table 2}

NATREX dynamics of exchange rate and external debt: Two Basic Scenarios

\begin{tabular}{|l|l|l|}
\hline Scenarios & $\begin{array}{l}\text { Medium- } \\
\text { run, } \\
\mathrm{T}=1\end{array}$ & $\begin{array}{l}\text { Longer-run } \\
\mathrm{T}=2\end{array}$ \\
\hline $\begin{array}{l}\text { Populist: } \\
\text { Rise in social in social consumption (discount rate, } \\
\text { time preference), rise in high employment government } \\
\text { budget deficit, decline social saving }\end{array}$ & $\begin{array}{l}\text { appreciation } \\
\mathrm{R}(1)>\mathrm{R}(0) \\
\text { Debt rises } \\
\mathrm{F}(1)>\mathrm{F}(0)\end{array}$ & $\begin{array}{l}\text { depreciation } \\
\mathrm{R}(2)<\mathrm{R}(0)<\mathrm{R}(1) \\
\text { Debt rises } \\
\mathrm{F}(2)>\mathrm{F}(1)>\mathrm{F}(0)\end{array}$ \\
\hline $\begin{array}{l}\text { Growth oriented: } \\
\text { Rise in productivity of investment, expansion of } \\
\text { production possibility set. Rise in growth, rise in } \\
\text { competitiveness }\end{array}$ & $\begin{array}{l}\text { appreciation } \\
\mathrm{R}(1)>\mathrm{R}(0) \\
\text { Debt rises } \\
\mathrm{F}(1)>\mathrm{F}(0)\end{array}$ & $\begin{array}{l}\mathrm{appreciation} \\
\mathrm{R}(2)>\mathrm{R}(1)>\mathrm{R}(0) \\
\mathrm{Debt} \text { declines } \\
\mathrm{F}(2)<\mathrm{F}(0)<\mathrm{F}(1)\end{array}$ \\
\hline
\end{tabular}

$\mathrm{R}=$ real exchange rate (rise is appreciation), $\mathrm{F}=$ external debt/GDP; initial period $\mathrm{T}=0$, medium run $\mathrm{T}=1$, long-run $\mathrm{T}=2$.

The Growth scenario is summarized in the lower half of table 1. Since the GDP/capital is $b=Y / K$, the growth of the GDP is $g$ in equation (15). It is the sum of two terms: (i) product of the current productivity of capital b and the investment ratio (I/Y) and (ii) the growth of the productivity of capital $\mathrm{db} / \mathrm{b}$.

(15) $g=d Y / Y=b(I / Y)+d b / b$

The perturbation is a rise in the productivity of investment $b$ and an expansion of the production possibility set. Investment rises because of the rise in $b$ the rate of return. The difference between investment and saving is financed by a capital inflow. The exchange rate appreciates to $\mathrm{R}(1)>\mathrm{R}(0)$ which reduces the trade balance and produces a current account deficit. The initial current account deficit equal to $[\mathrm{I}(0)-\mathrm{S}(0)]$ raises the debt. The trade deficit is used to obtain the resources to finance capital formation, which raises the growth rate and the competitiveness of the economy. 
It does not matter much where the rise in the return on investment occurred or what factors led to an expansion of the production possibility set. If they are in the traditional export or import competing sectors, the trade balance function $B=B(R ; b)$ increases. The B function, which relates the real value of the trade balance to the real exchange rate $R$, increases with a rise in $b$ and in the overall productivity of the economy. For example, the reallocation of resources leads to the production of higher quality/value goods that can compete in the world market. If the rate of return on investment and productivity increase in the sectors that are not highly involved in international trade, resources can then be released for use in the more traditional "tradable" sectors. Again, the B function supply curve increases.

The identification of "tradable" with manufacturing and "nontradable" with services sectors is problematic. For example services of all kinds, especially financial services, are very important exports for the United States, and cannot be considered as "nontradable". Another example is that the trends in the real exchange rate of both the major countries, the EU as well as the CEEC are dominated by the real exchange of "traded" goods, and the relevance of the Balassa-Samuelson effect is difficult to discern, as shown by Duval (2002) for the synthetic euro-\$US real exchange rate.

When the return on investment $b$ and productivity rise as a result of the more efficient allocation of resources, saving, investment, the growth rate and trade balance function increase. Investment increases because it is positively related to the net return on capital $(b-r)$. The rise in the productivity of capital raises the growth rate in (15) because both terms rise. Saving/GDP is ultimately positively related to the productivity of capital $\mathrm{b}$ and negatively to the discount rate. Saving less investment tends to rise. The rise in productivity $\mathrm{b}$ increases the trade balance $\mathrm{B}=\mathrm{B}(\mathrm{R} ; \mathrm{b})$ at any real exchange rate.

The trajectory to longer-run equilibrium differs from that in the Populist scenario. The crucial aspect implied by the Growth Scenario is that, at medium run equilibrium exchange rate $\mathrm{R}(1)$, the trade balance function increases relative to the saving less investment function. The real exchange rate appreciates and there are now current account surpluses, excess of saving over investment. As a result, the debt then declines to a new equilibrium $F(2)<F(0)$. The trajectory of the debt is not monotonic. The net effect in the longer-run can be understood from equation (12). The debt is lower, the growth rate is 
higher and the trade balance function B has shifted to the right. The long-run equilibrium exchange rate must appreciate to reduce $B$ to equal the lower value of $(r-g) F^{*}$.

The dynamic process in the Growth scenario is summarized in the lower half of table 2. The real exchange rate appreciates steadily to a higher level $R(2)>R(1)>R(0)$. The external debt reaches a maximum and then declines to $\mathrm{F}(2)<\mathrm{F}(0)<\mathrm{F}(1)$.

\subsection{The Nominal Exchange Rate: PPP and the NATREX}

The most frequently used estimate of the equilibrium nominal exchange rate is based upon the Purchasing Power Parity PPP hypothesis. The NATREX model is very different from the Purchasing Power Parity PPP hypothesis. The PPP arbitrarily assumes that the equilibrium real exchange rate is a constant. PPP is not based upon economic theory, and the associated studies are simply eclectic-econometric exercises. PPP cannot and does not purport to explain what determines the equilibrium exchange rate, what are the effects of policy/control variables and exogenous variables upon the equilibrium real exchange rate. Hence it is not particularly useful for policy questions. For example, PPP is unable to answer the following significant questions: At what exchange rate should the CEEC enter the Euro area, to avoid the problems that occurred with the integration of East Germany? What policies will be consistent or inconsistent with the established exchange rates to avoid deflationary or inflationary pressures? How can one explain the trends in the values of the Euro and the US dollar? How can one derive Early Warning Signals of an exchange crisis such as Thailand in $1997 ?$

The NATREX model implies that one would observe PPP in the long-run only if $R\left(Z_{t}\right)$ in equation (13), a linear combination of the fundamentals, is mean reverting in the longer run. The PPP model is a special case of the NATREX model. The relation between the two models can be understood from figure 1-4 and equation (16). The logarithm of the equilibrium nominal exchange rate ${ }^{33}$ denoted $\log \mathrm{N}_{\mathrm{t}}^{\mathrm{e}}$ has two components: the logarithm of the equilibrium real exchange rate, $\log R\left[Z_{t}\right]$ which is the NATREX, and the logarithm of the ratio of relative domestic/foreign "prices" ${ }^{34}$ denoted

\footnotetext{
${ }^{33}$ A rise in the nominal or real exchange rate is an appreciation of the currency.

${ }^{34}$ The best choices are either relative GDP deflators or relative labor costs.
} 
$\log \left[\mathrm{p}_{\mathrm{t}} / \mathrm{p}_{\mathrm{t}} \mathrm{t}\right.$. The PPP ignores the $\mathrm{R}\left(\mathrm{Z}_{\mathrm{t}}\right)$ term by assuming that it is a constant, and focuses exclusively upon the relative price term. The NATREX is not a constant, but varies with the vector of fundamentals $Z_{t}$ that underlie the saving, investment and trade balance functions.

(16) $\log \mathrm{N}_{\mathrm{t}}^{\mathrm{e}}=\log \mathrm{R}\left[\mathrm{Z}_{\mathrm{t}}\right]-\log \left[\mathrm{p}_{\mathrm{t}} / \mathrm{p}_{\mathrm{t}} \mathrm{t}_{\text {. }}\right.$

Figure 1- 4 describes three values of $R(Z)$, where $R(Z=1)$ is the most appreciated NATREX, $R(Z=2)$ is the most depreciated value and $R(Z=0)$ is the mean NATREX. Suppose that $\mathrm{Z}=0$ and the corresponding equilibrium real exchange rate NATREX is $\mathrm{R}(0)$. Then the equilibrium nominal exchange rate is a set of points along line $\mathrm{R}(0)$. The PPP relation would hold as long as the NATREX remained constant. If the nominal exchange rate were above the line $\mathrm{R}(0)$, the currency is overvalued. There cannot be internal and external equilibrium. The country would have difficulty competing in international markets. It would either lose reserves and the external debt/GDP ratio would rise, or there would be depressed economic conditions, particularly if the monetary/fiscal authorities attempt to stem the excess demand for foreign exchange. Similarly, if the nominal exchange rate were below the line, then reserves would rise or there would be inflationary pressures. Nominal exchange rates either above or below the line are unsustainable. Either the nominal exchange rate or relative prices must adjust, if both internal and external equilibrium are to prevail. 


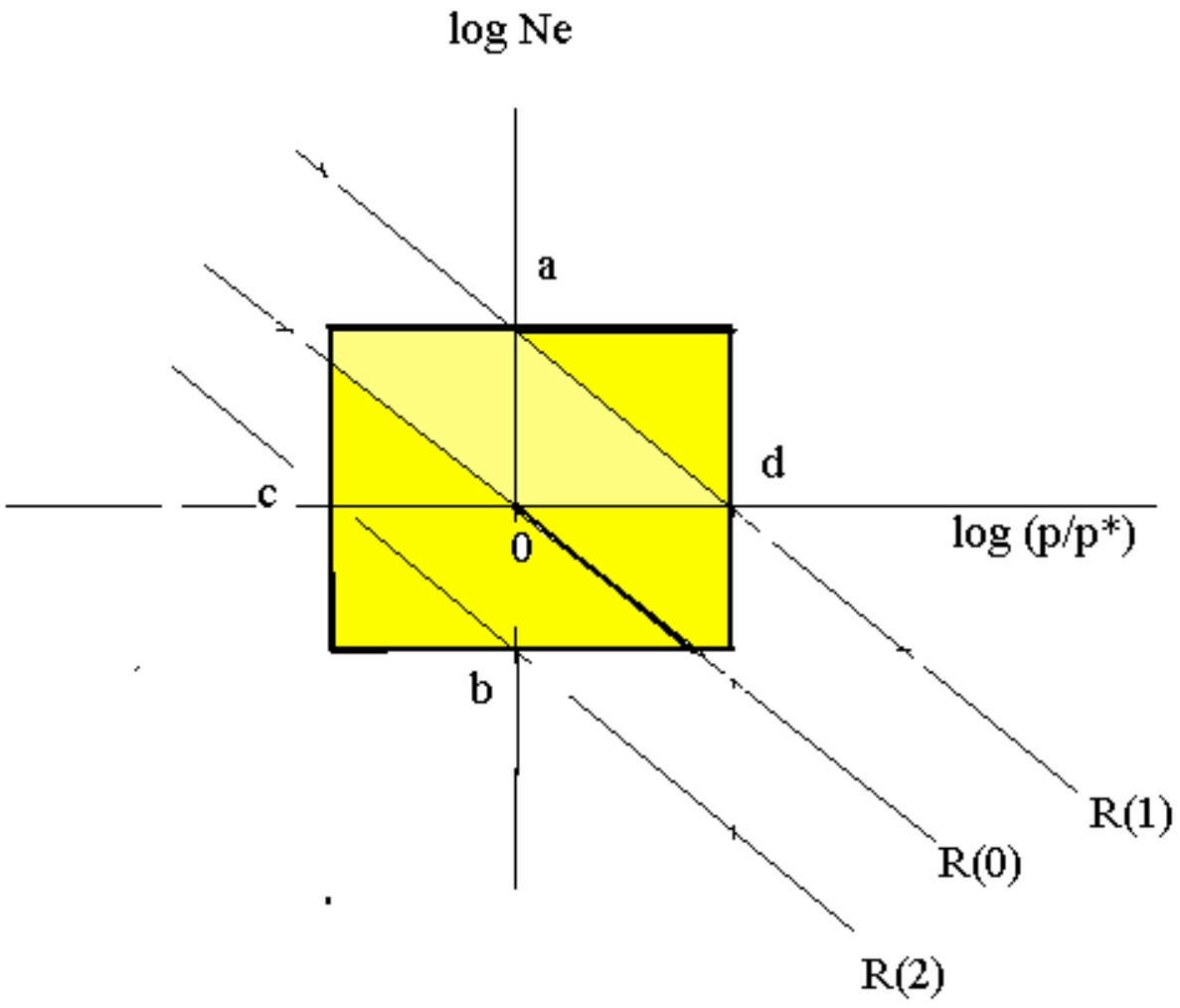

Figure 1-4. The equilibrium nominal exchange rate, the NATREX and relative prices. If the NATREX varies between $\mathrm{R}(1)$ and $\mathrm{R}(2)$, and relative prices vary between $\mathrm{c}$ and $\mathrm{d}$, the equilibrium nominal exchange rate will be contained in the rectangle.

The NATREX changes with the fundamentals vector $Z_{t}$, as described in the two scenarios summarized in section table 2 . As the NATREX varies between $R(1)$ and $R(2)$ and relative prices vary between $\mathrm{c}$ and $\mathrm{d}$, the equilibrium nominal exchange rate will be contained in the rectangle. A regression of the nominal exchange rate upon relative prices would be based upon the scatter of points in the rectangle. If the relative prices are constant at $\log \left[\mathrm{p}_{\mathrm{t}} / \mathrm{p}_{\mathrm{t}}{ }_{\mathrm{t}}\right]=0$, then the equilibrium nominal exchange rate varies from $a$ to $b$. If the nominal exchange rate is fixed at $\log \mathrm{N}_{\mathrm{t}}=0$, then relative prices must vary between $c$ and $d$. 


\section{Examples: NATREX as a guide to Policy - The Euro and the United States Dollar}

The NATREX model can be a guide to policy. It can help to answer the question: what policies should be followed such that the nominal exchange rate is sustainable. The only way to evaluate if the nominal exchange rate is consistent with the equilibrium in equation (16) is to directly estimate the NATREX in equation (13) and use this estimate as $\mathrm{R}\left[\mathrm{Z}_{\mathrm{t}}\right]$ in (16) along with an estimate of relative prices. We now provide several examples as to how this is done.

A lesson for the CEEC who are contemplating entering into the Euro area is to evaluate whether the selected nominal exchange rate is consistent with equations (13) and (16). If the nominal rate is above the line, the economies will be depressed like eastern Germany. If the nominal rate is below the line in figure 1-4, there will be inflationary pressures. In either case, the situation will not be sustainable. It would be a grave error for the CEEC to adopt the Euro without understanding what is their appropriate NATREX ${ }^{35}$.

The PPP hypothesis focuses solely upon relative prices and ignores variations in the NATREX, which are primarily the result of the Populist and Growth scenarios described above. Initially, the NATREX may be $\mathrm{R}(0)$ and relative prices and the nominal exchange rate are at the origin. If Populist policies are then followed, the NATREX will decline to $\mathrm{R}(2)$ and the currency will be overvalued. If Growth policies lead to a NATREX of R(1), then there will be inflationary pressures. The NATREX model allows one to evaluate to what extent the change in the equilibrium nominal exchange rate is due to vertical shifts of the $R(Z)$ curve - variations in the equilibrium real exchange rate - and to what extent it is due to movements along the curve - variations in relative prices.

With the introduction of the Euro in 1999, there was a multitude of predictions concerning its future value relative to the U.S. dollar. During the period that the euro fell below \$0.90/euro and later rose above \$1.20/euro, there was a profusion of ephemeral ad hoc and contradictory explanations. Researchers at the European Central Bank and in Western Europe in particular approached the issue scientifically. They constructed a synthetic euro, which is a weighted average of the component currencies from 1970 to

\footnotetext{
${ }^{35}$ Significant studies concerning the equilibrium exchange rate for the CEEC are by: Égert, Tober and Lommatzsch, Frait and Komarek, Breuss, Halpern and Fischer (Bundesbank). These articles have been influenced by the NATREX method of analysis.
} 
2000. The challenge was to test alternative hypotheses concerning the determinants of the value of the euro and then comparing their relative explanatory power ${ }^{36}$. The theory that successfully explained the evolution of the synthetic euro would presumably be the most useful model to use for the actual euro. A comprehensive collection of these studies of exchange rates in Europe was published in the Australian Economic Papers in 2002.

The researchers concluded that NATREX model sketched above was quite successful relative to the others in explaining exchange rate variations ${ }^{37}$. An example of the results concerning the Euro and the U.S. dollar has been used as a model for the CEEC in the studies, for example by Egert and his co-authors. The NATREX states that the fundamental determinants of the real exchange rate $R\left(Z_{t}\right)$ and the debt ratio $F_{t}$ are the variables $\mathbf{Z}_{\mathbf{t}}$ in table 2: relative social consumption ratio, relative productivity of investment, and relative productivity of labor in the pair of countries considered. The signs of their medium run and long run effects are specified in table 2.

The debt ratio is an endogenous variable and should not be used as a regressor in the exchange rate equation. The empirical studies that use the debt ratio $^{38}$ as a regressor often obtain the bizarre result that a rise in the debt appreciates the exchange rate. Some studies find that the debt variable is not significantly significant. Table 2 explains why these bizarre results are obtained. For the Populist disturbance, the exchange rate first appreciates and then depreciates, but the debt ratio rises steadily. For the Growth disturbance, the exchange rate appreciates steadily, but the debt first rises and then falls. Hence regression analysis of the exchange rate that contains the debt ratio will generate the "bizarre" results mentioned.

Using the fundamentals $Z_{t}$ for the Euro area relative to the US, one obtains an estimate of the NATREX labeled $R(Z)$. The coefficients have the signs specified in the model, table 2. Adding the relative price variable, we obtain an estimate of equation (16) for the equilibrium nominal value of the Euro. A rise is an appreciation of the Euro or a depreciation of the United States dollar. Figure 1-5 graphs the actual nominal value of

\footnotetext{
${ }^{36}$ Very few of the models that feature prominently in the graduate textbooks in international finance were operational and even remotely consistent with the data. Hence they were not featured in the published research of the ECB staff and by economists in Europe concerned with the Euro and the CEEC.

${ }^{37}$ Some studies estimate reduced form equations and others the structural equations of the model. Noteworthy studies are by Detken, Dieppe, Henry, Marin and Smets (2002), Detken and Marin (2001) and Duval (2002). See also European Central Bank (2002).

${ }^{38}$ These studies cumulate the current account deficit to obtain a measure of the debt.
} 
the synthetic euro (EUUSNERMA = \$US/euro) and the estimate of the equilibrium nominal value (NOMNAT), based upon the NATREX.

The NATREX is a model of the equilibrium exchange rate, not the actual exchange rate. The actual exchange rate is hypothesized to converge to a distribution whose mean is the equilibrium exchange rate. The equilibrium rate varies according to figure 1-4, equation (16) - because there are both shifts in the $R(Z)$ curve as well as movements along the curves due to relative prices. Since the equilibrium nominal exchange rate varies with both vector $Z_{t}$ and relative prices $\left(\mathrm{p}_{\mathrm{t}} / \mathrm{p}_{\mathrm{t}}{ }^{*}\right)$, price stability alone is not a sufficient condition for exchange rate sustainability.

Figure 1-5 shows the undervaluation of the synthetic euro (the overvaluation of the SUS) in the first half of the 1980's, and in the period after 1996. Estimates of the equilibrium value of the Euro from 1999 - 2001 indicated that it was undervalued relative to the \$US. This estimate is consistent with the significant appreciation of the Euro since 2001. The euro appreciated from $\$ 0.85$ in 2001 to $\$ 1.29$ in November 2004. We have therefore indicated how the NATREX model can be and has been implemented to explain exchange rate variations. 


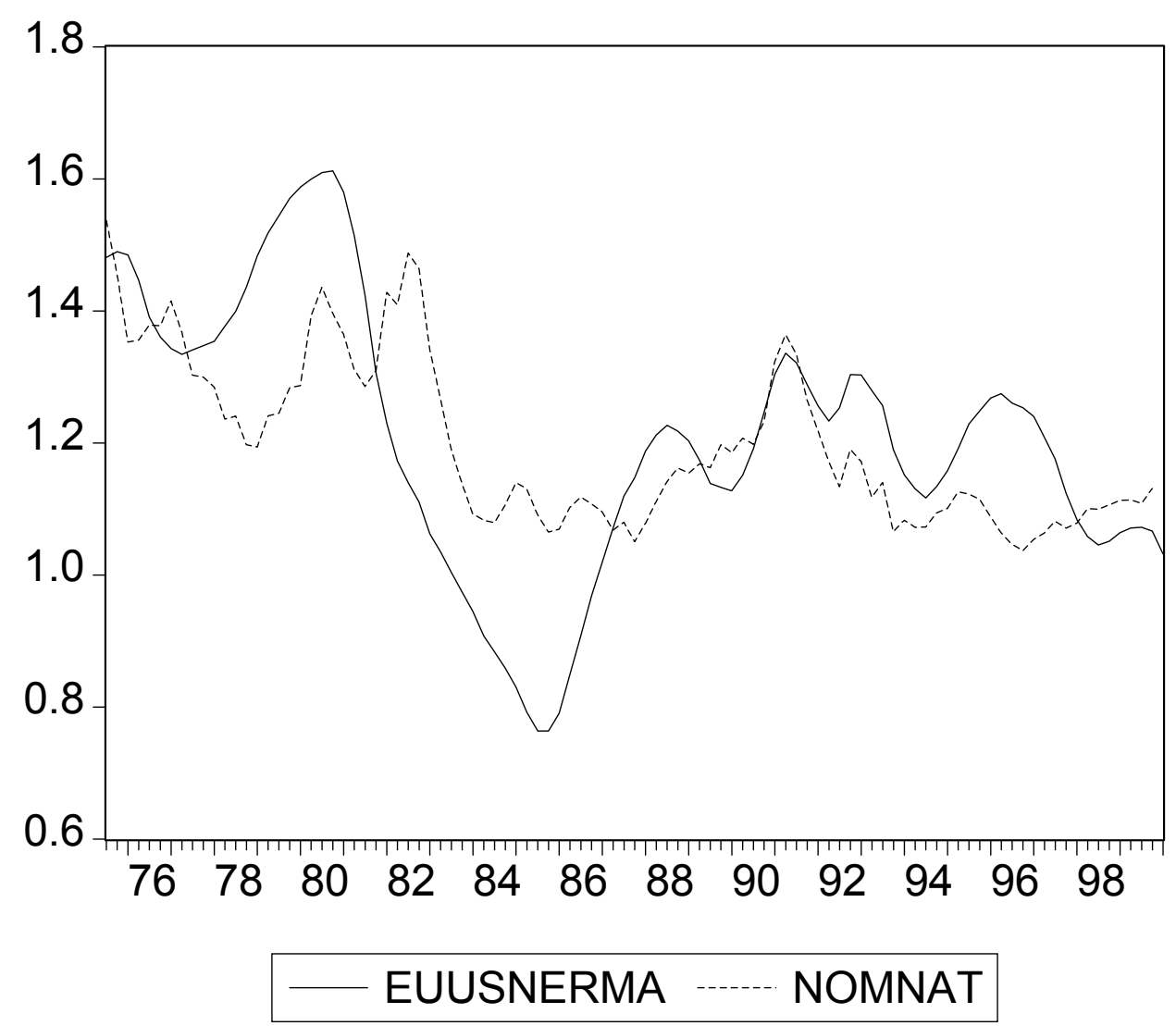

Figure 1-5. Nominal value synthetic euro (4 Q MA), \$US/Euro = EUUSNERMA; NATREX estimate, equation (16) is NOMNAT, 1970 to 2000. 


\section{Interaction Misaligned Exchange Rate and Unsustainable Debt}

A large literature concerns warning signals for both balance of payments/currency crises and debt crises. The method of analysis generally estimates a family of probit models to assess the predictability of some vector in anticipating each type of crisis. The method of analysis is eclectic-econometric. In section 7.1 we briefly discuss this literature. Section 7.2 gives an example ${ }^{39}$, the Thailand crises 1997-98, of how our analysis of misaligned exchange rates and excess debt differs from the eclecticeconometric approach in the literature.

\subsection{A sketch of the literature ${ }^{40}$}

Relations $[\mathrm{A}]$ - [E] summarize the literature. In each case, probit analysis or something similar is used to evaluate what vector $\mathrm{V}$ is the best, or at least a useful, predictor or Warning Signal WS. The standards against which the WS is evaluated are of several types. First, is the Sovereign rating $S R$ of the major rating agencies Moodys and Standard \& Poor. Second, are the available measures of expectations by the market. They are of two types: direct measures of expectations from surveys, and those embodied in asset prices, such as interest rate differentials.

Sovereign ratings SR use all available information, vector V. Studies [A] conclude that vector $V$ consists of: per capita GDP, inflation, external debt/exports, default history. After 1998, the vector was extended to include bank assets/GDP and interest rate differentials. Studies examined [B] whether the SR were able to predict the debt crises. Credit rating agencies argue that SR are used to provide an assessment of the likelihood of default, not the likelihood of a currency crisis. However, the macrovariables in vector $\mathrm{V}$ are expected to be relevant for crises in general. Therefore, some studies [D] inquire whether the vector $\mathrm{V}$ is a useful predictor of balance of payments crises.

Most of the studies are concerned with currency/balance of payments crises. The components of vector $W$, which were deemed most useful in predicting balance of

\footnotetext{
${ }^{39}$ A detailed discussion of the application of our analysis to Asian crisis is the subject of chapter six.

${ }^{40}$ Key articles underlying this sketch are by: Berg et al (1999), International Monetary Fund WEO (October ,1998), Kaminsky and Reinhart (1999), Cantor and Packer (1996) and Sy (2004). Extensive references to the literature are found in these articles. The definitions of each type of crisis and the sample periods are in the cited articles.
} 
payments crisis [C] are: real exchange rate relative to its trend, domestic credit growth, $\mathrm{M} 2 /$ reserves, current account deficits short term debt/reserves and reserve losses.

[A] Sovereign rating $\Leftarrow$ Vector $V$

[B] Probability of a Debt crisis $\Leftarrow$ Sovereign rating

[C] Probability of a Balance of payments crisis $\Leftarrow$ Vector $W$

[D] Probability of a Balance of payments crisis $\Leftarrow$ Sovereign rating

[E] Interaction of the two types of crisis

The conclusions of the extensive studies are not particularly encouraging. First: the Warning signals from vector $\mathrm{W}$ in $[\mathrm{C}]$ had mixed successes. Berg et al show that a representative model produces a warning signal in 50\% of the cases in which it should have signaled a balance of payments crisis. However, in about $60 \%$ of the times that the typical model issued a warning, no crisis occurred in the following 24 months.

Second: neither the rating agencies nor the market provided reliable indicators of crises. They failed to predict the Mexican and Asian crises. For example, market anticipations as embedded in interest rate differentials did not widen significantly prior to the Mexican crisis. In the Asian countries, spreads hardly increased in the months before the flotation of the baht.

The lesson from these studies stated by several of the authors, is that one should ask whether the determinants of the ratings vector $\mathrm{V}$ in $[\mathrm{A}]$ is the right set of "fundamentals" to predict financial crises. Clearly, the negative results suggest that there may be variables other than those in vectors $V$ and $W$ that determine crises. Our theme is that the theoretical analyses of misaligned exchange rates and excess debt that are sketched in parts 2,3 and 5 above are useful complements of the eclectic-econometric approach.

\subsection{Thailand Example}

We conclude this overview of "Optimal Debt and Equilibrium Exchange Rates" with the example of the 1997 crisis in Thailand. This crisis was shortly followed by the other Asian crises, which are discussed in chapter six. In the Thai case, the two types of crises - currency and debt - interacted with each other. This example shows how our analysis differs from the eclectic-econometric approach described in section 7.1 above. 
When the exchange rate is overvalued then: if output is at capacity, reserves decline and the debt ratio rises. Or if restrictive monetary and fiscal policies are implemented to avoid a loss of reserves and growth of the external debt, the economy is depressed. The first case characterized the Asian economies before the 1997-98 crisis.

In the Southeast Asian countries, the governments sponsored and encouraged industrialization policies. Investment rose relative to saving and the external debt increased, without a rise in the return on investment. In Thailand, there was an interaction between a misaligned real exchange rate and an excess debt ${ }^{41}$. Figures 1-6 and 1-7 illustrate these two sources of vulnerability.

Misalignment $\Phi_{\mathrm{t}}=\mathrm{R}_{\mathrm{t}}-\mathrm{R}\left[\mathrm{Z}_{\mathrm{t}}\right]$ is the deviation between the actual real exchange rate $R_{t}$ and $R\left[Z_{t}\right]$ the NATREX, which is calculated on the basis of available information up to time $t$, as explained in chapter six. The NATREX is based upon the fundamental variables in table 2: the social consumption or time preference, the productivity of labor and the return on real investment. Figure 1-6 shows that the Baht was overvalued misalignment $\Phi_{t}>0$ - for a sustained period of time prior to the crisis. The main reasons for the decline in the NATREX were that the productivity of investment was declining and the time preference was rising.

Since the exchange rate was overvalued $\Phi_{t}>0$, the debt ratio was rising and a crisis was becoming more probable. Insofar as the exchange rate was overvalued, it could be expected to depreciate towards the NATREX- unless there are short-term capital inflows to compensate for a negative current account plus non-speculative capital account. Given the rise in the debt ratio, it was not likely that foreign creditors would increase their positions at risk.

The rise in the external debt ratio during a period when the expected net return on capital (b-r) was declining meant that the debt ratio was rising above curve U-S in figure 1-2. Figure 1-7 shows that this situation occurred in Thailand prior to the 1997-98 crisis. The excess debt $\Psi_{\mathrm{t}}=\mathrm{F}_{\mathrm{t}}-\mathrm{f}_{\mathrm{t}}>0$ implies that the economy is more vulnerable to external shocks. The expected growth rate declines and its variance rises. Insofar as the exchange rate depreciates, the real rate of interest rises because more consumer goods must be sacrificed to service the dollar denominated debt. Equation (2), repeated here, shows that

\footnotetext{
${ }^{41}$ The same was true for Korea, as shown in chapter six.
} 
as the growth of GDP declines and the real rate of interest rises, consumption must decline - unless there is an infusion of external capital.

(2) $C_{s} d s=\left(Y_{s}-r_{s} L_{s}-I_{s}\right) d s+d L_{s}$

In the Thai conditions, such a short-term capital inflow would not be justified. In fact, it is rational that there be be a short-term capital outflow. Then one would observe a drastic depreciation of the exchange rate, which falls below the NATREX, and a debt crisis where the country cannot service its debt without a sustained and significant reduction of consumption.

This example from Thailand shows how the two deviations, misalignment $\Phi_{\mathrm{t}}=\mathrm{R}_{\mathrm{t}}-\mathrm{R}\left[\mathrm{Z}_{\mathrm{t}}\right]>0$ and excess debt $\Psi_{\mathrm{t}}=\mathrm{F}_{\mathrm{t}}-\mathrm{f}_{\mathrm{t}}>0$, interact to produce crises. The misalignment is based upon the NATREX model and the excess debt is derived from the stochastic optimal control. In this manner, we give theoretical precision to the concept of vulnerability. This Overview chapter has described in relatively non-technical terms the contributions of the other chapters of this book. 


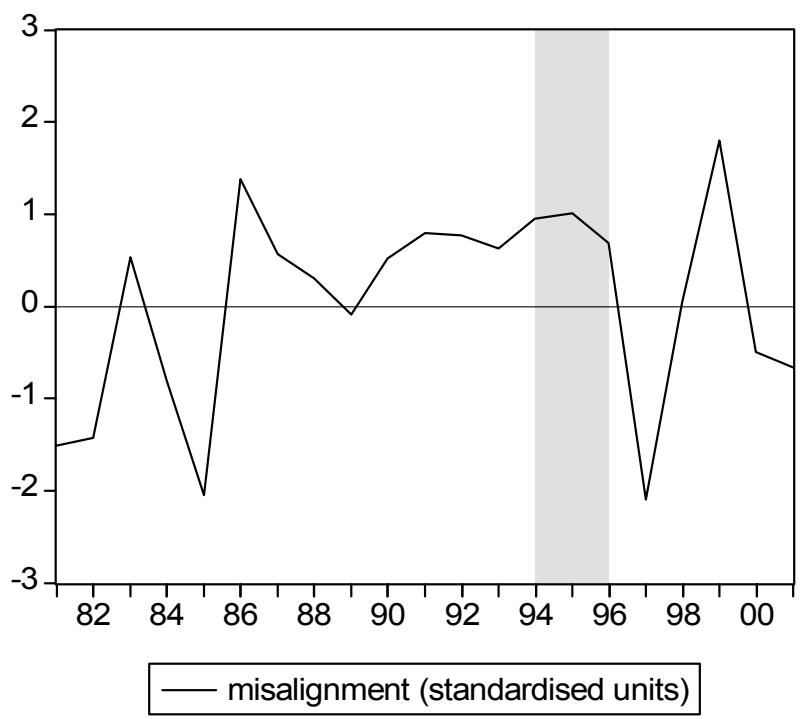

Figure 1-6. Real exchange rate Misalignment in Thailand, $\Phi_{t}=R_{t}-R\left[Z_{t}\right]>0$, where $\mathrm{R}\left[\mathrm{Z}_{\mathrm{t}}\right]$ is the NATREX. The shaded area is pre-crisis. Normalized variables.

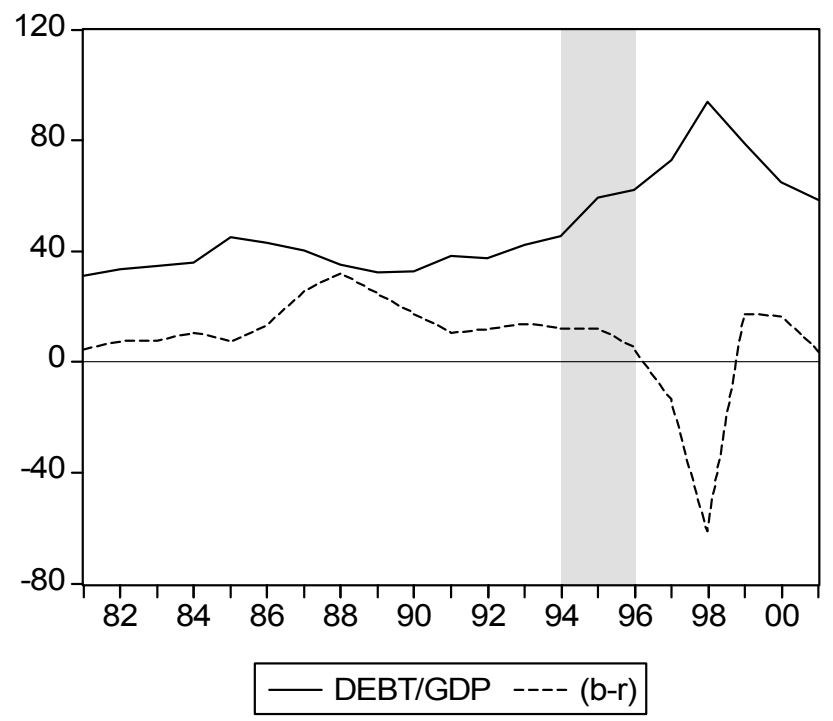

Figure 1-7. Thailand. Debt/GDP ratio and net return on investment (b-r). Shaded period is the pre-crisis period. 


\section{REFERENCES}

Allen, Polly R. (1997), The Economic and Policy Implications of the NATREX Approach, in Stein, Jerome L., Polly Allen et al (1997) Fundamental Determinants of Exchange Rates, Oxford University Press, chapter 1.

Berg, A., E. et al, (1999) Anticipating Balance of Payments Crises The Role of Early Warning Systems, International Monetary Fund, Occasional Paper 186.

Breuss, Fritz (2003) Balassa-Samuelson Effects in the CEEC, Research Institute for European Affairs, University of Economics and Business Administration Vienna IEF WP \#52

Cantor, R., F. Packer (1996) Determinants and impact of sovereign credit ratings, Economic Policy Review, Federal Reserve Bank of New York, 2 October

Clark, Peter and Ronald MacDonald (1999), Exchange Rates and Economic Fundamentals: A Methodological Comparison of BEERs and FEERs in Ronald MacDonald and Jerome L. Stein (1999), Equilibrium Exchange Rates, Kluwer Academic

Detken, Carsten, Alistair Dieppe, Jérôme Henry, Carmen Marin and Frank Smets (2002) Determinants of the Effective Real Exchange Rate of the Synthetic Euro: Alternative Methodological Approaches, Australian Economic Papers, Special Issue on: Exchange Rates in Europe and in Australasia, December.

Detken, Carsten and Carmen Marin, (2001) The Effective Euro Equilibrium Exchange Rate Since the 1970's: A Structural Natrex Estimation, European Central Bank, Working paper, available at $<$ webdeptos.uma.es $>$

Deutsche Bundesbank, (1998) "Economic Conditions in eastern Germany", Monthly Report, April

Dornbusch, Rudiger (2003), International Financial Crises, CESifo Working Paper \#206.

Driver, Rebecca and Peter F. Westaway (2005), "Concepts of equilibrium exchange rates", in Rebecca Driver, P. Sinclair and C. Thoenissen (ed.) Exchange Rates, Capital Flows and Policy", Routledge.

Duval, Romain (2002), What do we know about the long-run equilibrium real exchange rates? PPP vs. macroeconomic balance approach, Australian Economic Papers (2002) Special Issue on: Exchange Rates in Europe and in Australasia, December.

Égert, Balazs (2003), Assessing Equilibrium Exchange Rates in the CEEC Acceding Countries: Can we have DEER without BEER without FEER? A critical survey of the literature, William Davidson Institute, University of Michigan, WP \# 664 
Égert, Balázs and L. Halpern (2004), Equilibrium Exchange Rates in Central and Eastern Europe: A meta-regression analysis, Austrian National Bank, mimeo.

Égert, Balázs and and K. Lommatzsch (2004), Equilibrium Exchange Rates in the transition: The tradable price-based real appreciation and estimation uncertainty, William Davidson Institute, University of Michigan, WP \#676

European Central Bank (2002), Monthly Bulletin, Economic Fundamentals and the Exchange Rate of the Euro, January, 41 - 53.

Fischer, Christoph(2004) Real Currency appreciation in accession countries: BalassaSamuelson and investment demand, Review of World Economics, Weltwirtschaftliches Archiv, 140 (2)

Fleming,Wendell H. and Jerome L. Stein, (2004), Stochastic Optimal Control, International Finance and Debt, Journal of Banking and Finance.

Fleming,Wendell H.and Jerome L. Stein, (2001), Stochastic Inter-temporal Optimization in Discrete Time, in Negishi,Takashi, Rama Ramachandran and Kazuo Mino (ed) Economic Theory, Dynamics and Markets: Essays in Honor of Ryuzo Sato, Kluwer, Boston.

Fleming, Wendell H. (2004) Some Optimal Investment, Production and Consumption Models, American Mathematical Society, Contemporary Mathematics.

Fleming, Wendell H. (2005) Optimal Investment and Consumption Models with Minimum Consumption Criteria, Australian Economic Papers, to appear

Frait, Jan and Lubos Komárek (2001) Real Exchange Rate Trends in Transitional Countries, Warwick Economic Research Paper, \#596

Gandolfo, Giancarlo (2001), International Finance and Open-Economy Macroeconomics, Springer

Infante, E. F. and Jerome L. Stein (1973) Optimal Growth with Robust Feedback Control, Rev. Econ. Stud. 40 (1).

International Monetary Fund (2004), Independent Evaluation Office (IEO), Report on the Evaluation of the Role of the IMF in Argentina, 1991-2001.

International Monetary Fund (1998) World Economic Outlook, October

Kaminsky, G. and C. Reinhart (1999) The Twin Crises: The Causes of Banking and Balance of Payments Problems, Amer. Econ. Rev. 89 (3)

Lommatzsch, K. and Tober (2002), What is behind the real Appreciation of the accession 
countries' currencies German Institute of Economic Research, Berlin

MacDonald, Ronald and Jerome L. Stein (1999), Equilibrium Exchange Rates, Kluwer.

Merton, Robert (1990), Continuous Time Finance, Blackwell.

Mussa, Michael (2002) Argentina and the Fund: From Triumph to Tragedy, Institute for International Economics, Washington, DC

Stein, Jerome L. and Giovanna Paladino (2001) Country Default Risk: An Empirical Assessment, Australian Economic Papers, 40, (2), December

Stein, Jerome L, Polly R. Allen et al, $(1995,1997)$ Fundamental Determinants of Exchange Rates, Oxford University Press

Stein, Jerome L. (2002) The Equilibrium Real Exchange Rate of the Euro: An Evaluation of Research, ifo Studien, 3/2002

Stein, Jerome L. and Guay C. Lim (2002) Introduction to Exchange Rates in Europe and Australasia: Fundamental Determinants, Adjustments and Policy Implications, Australian Economic Papers, 41 (4), December

Stein, Jerome L. and Guay C. Lim (2004) Asian Crises: Theory, Evidence and Warning Signals, Singapore Economic Review

Stein, Jerome L.(2004) Stochastic Optimal Control Modeling of Debt Crises, American Mathematical Society, Contemporary Mathematics

Sy, A. (2004) Rating the Rating Agencies, Jour. Bank. \& Finan. 28 (11)

Turnovsky, S. (2000) Methods of Macrodynamics, MIT Press

Williamson, John (1994) Estimating Equilibrium Exchange Rates, Institute for International Economics, Washington, DC 


\title{
CESifo Working Paper Series
}

\author{
(for full list see www.cesifo.de)
}

1301 Alan V. Deardorff, Who Makes the Rules of Globalization?, October 2004

1302 Sheilagh Ogilvie, The Use and Abuse of Trust: Social Capital and its Deployment by Early Modern Guilds, October 2004

1303 Mario Jametti and Thomas von Ungern-Sternberg, Disaster Insurance or a Disastrous Insurance - Natural Disaster Insurance in France, October 2004

1304 Pieter A. Gautier and José Luis Moraga-González, Strategic Wage Setting and Coordination Frictions with Multiple Applications, October 2004

1305 Julia Darby, Anton Muscatelli and Graeme Roy, Fiscal Federalism, Fiscal Consolidations and Cuts in Central Government Grants: Evidence from an Event Study, October 2004

1306 Michael Waldman, Antitrust Perspectives for Durable-Goods Markets, October 2004

1307 Josef Honerkamp, Stefan Moog and Bernd Raffelhüschen, Earlier or Later: A General Equilibrium Analysis of Bringing Forward an Already Announced Tax Reform, October 2004

1308 M. Hashem Pesaran, A Pair-Wise Approach to Testing for Output and Growth Convergence, October 2004

1309 John Bishop and Ferran Mane, Educational Reform and Disadvantaged Students: Are They Better Off or Worse Off?, October 2004

1310 Alfredo Schclarek, Consumption and Keynesian Fiscal Policy, October 2004

1311 Wolfram F. Richter, Efficiency Effects of Tax Deductions for Work-Related Expenses, October 2004

1312 Franco Mariuzzo, Patrick Paul Walsh and Ciara Whelan, EU Merger Control in Differentiated Product Industries, October 2004

1313 Kurt Schmidheiny, Income Segregation and Local Progressive Taxation: Empirical Evidence from Switzerland, October 2004

1314 David S. Evans, Andrei Hagiu and Richard Schmalensee, A Survey of the Economic Role of Software Platforms in Computer-Based Industries, October 2004

1315 Frank Riedel and Elmar Wolfstetter, Immediate Demand Reduction in Simultaneous Ascending Bid Auctions, October 2004 
1316 Patricia Crifo and Jean-Louis Rullière, Incentives and Anonymity Principle: Crowding Out Toward Users, October 2004

1317 Attila Ambrus and Rossella Argenziano, Network Markets and Consumers Coordination, October 2004

1318 Margarita Katsimi and Thomas Moutos, Monopoly, Inequality and Redistribution Via the Public Provision of Private Goods, October 2004

1319 Jens Josephson and Karl Wärneryd, Long-Run Selection and the Work Ethic, October 2004

1320 Jan K. Brueckner and Oleg Smirnov, Workings of the Melting Pot: Social Networks and the Evolution of Population Attributes, October 2004

1321 Thomas Fuchs and Ludger Wößmann, Computers and Student Learning: Bivariate and Multivariate Evidence on the Availability and Use of Computers at Home and at School, November 2004

1322 Alberto Bisin, Piero Gottardi and Adriano A. Rampini, Managerial Hedging and Portfolio Monitoring, November 2004

1323 Cecilia García-Peñalosa and Jean-François Wen, Redistribution and Occupational Choice in a Schumpeterian Growth Model, November 2004

1324 William Martin and Robert Rowthorn, Will Stability Last?, November 2004

1325 Jianpei Li and Elmar Wolfstetter, Partnership Dissolution, Complementarity, and Investment Incentives, November 2004

1326 Hans Fehr, Sabine Jokisch and Laurence J. Kotlikoff, Fertility, Mortality, and the Developed World's Demographic Transition, November 2004

1327 Adam Elbourne and Jakob de Haan, Asymmetric Monetary Transmission in EMU: The Robustness of VAR Conclusions and Cecchetti's Legal Family Theory, November 2004

1328 Karel-Jan Alsem, Steven Brakman, Lex Hoogduin and Gerard Kuper, The Impact of Newspapers on Consumer Confidence: Does Spin Bias Exist?, November 2004

1329 Chiona Balfoussia and Mike Wickens, Macroeconomic Sources of Risk in the Term Structure, November 2004

1330 Ludger Wößmann, The Effect Heterogeneity of Central Exams: Evidence from TIMSS, TIMSS-Repeat and PISA, November 2004

1331 M. Hashem Pesaran, Estimation and Inference in Large Heterogeneous Panels with a Multifactor Error Structure, November 2004

1332 Maarten C. W. Janssen, José Luis Moraga-González and Matthijs R. Wildenbeest, A Note on Costly Sequential Search and Oligopoly Pricing, November 2004 
1333 Martin Peitz and Patrick Waelbroeck, An Economist's Guide to Digital Music, November 2004

1334 Biswa N. Bhattacharyay and Prabir De, Promotion of Trade, Investment and Infrastructure Development between China and India: The Case of Southwest China and East and Northeast India, November 2004

1335 Lutz Hendricks, Why Does Educational Attainment Differ Across U.S. States?, November 2004

1336 Jay Pil Choi, Antitrust Analysis of Tying Arrangements, November 2004

1337 Rafael Lalive, Jan C. van Ours and Josef Zweimueller, How Changes in Financial Incentives Affect the Duration of Unemployment, November 2004

1338 Robert Woods, Fiscal Stabilisation and EMU, November 2004

1339 Rainald Borck and Matthias Wrede, Political Economy of Commuting Subsidies, November 2004

1340 Marcel Gérard, Combining Dutch Presumptive Capital Income Tax and US Qualified Intermediaries to Set Forth a New System of International Savings Taxation, November 2004

1341 Bruno S. Frey, Simon Luechinger and Alois Stutzer, Calculating Tragedy: Assessing the Costs of Terrorism, November 2004

1342 Johannes Becker and Clemens Fuest, A Backward Looking Measure of the Effective Marginal Tax Burden on Investment, November 2004

1343 Heikki Kauppi, Erkki Koskela and Rune Stenbacka, Equilibrium Unemployment and Capital Intensity Under Product and Labor Market Imperfections, November 2004

1344 Helge Berger and Till Müller, How Should Large and Small Countries Be Represented in a Currency Union?, November 2004

1345 Bruno Jullien, Two-Sided Markets and Electronic Intermediaries, November 2004

1346 Wolfgang Eggert and Martin Kolmar, Contests with Size Effects, December 2004

1347 Stefan Napel and Mika Widgrén, The Inter-Institutional Distribution of Power in EU Codecision, December 2004

1348 Yin-Wong Cheung and Ulf G. Erlandsson, Exchange Rates and Markov Switching Dynamics, December 2004

1349 Hartmut Egger and Peter Egger, Outsourcing and Trade in a Spatial World, December 2004

1350 Paul Belleflamme and Pierre M. Picard, Piracy and Competition, December 2004 
1351 Jon Strand, Public-Good Valuation and Intrafamily Allocation, December 2004

1352 Michael Berlemann, Marcus Dittrich and Gunther Markwardt, The Value of NonBinding Announcements in Public Goods Experiments: Some Theory and Experimental Evidence, December 2004

1353 Camille Cornand and Frank Heinemann, Optimal Degree of Public Information Dissemination, December 2004

1354 Matteo Governatori and Sylvester Eijffinger, Fiscal and Monetary Interaction: The Role of Asymmetries of the Stability and Growth Pact in EMU, December 2004

1355 Fred Ramb and Alfons J. Weichenrieder, Taxes and the Financial Structure of German Inward FDI, December 2004

1356 José Luis Moraga-González and Jean-Marie Viaene, Dumping in Developing and Transition Economies, December 2004

1357 Peter Friedrich, Anita Kaltschütz and Chang Woon Nam, Significance and Determination of Fees for Municipal Finance, December 2004

1358 M. Hashem Pesaran and Paolo Zaffaroni, Model Averaging and Value-at-Risk Based Evaluation of Large Multi Asset Volatility Models for Risk Management, December 2004

1359 Fwu-Ranq Chang, Optimal Growth and Impatience: A Phase Diagram Analysis, December 2004

1360 Elise S. Brezis and François Crouzet, The Role of Higher Education Institutions: Recruitment of Elites and Economic Growth, December 2004

1361 B. Gabriela Mundaca and Jon Strand, A Risk Allocation Approach to Optimal Exchange Rate Policy, December 2004

1362 Christa Hainz, Quality of Institutions, Credit Markets and Bankruptcy, December 2004

1363 Jerome L. Stein, Optimal Debt and Equilibrium Exchange Rates in a Stochastic Environment: an Overview, December 2004 